This item was submitted to Loughborough's Research Repository by the author.

Items in Figshare are protected by copyright, with all rights reserved, unless otherwise indicated.

\title{
Simplified modelling of vehicle interior noise: comparison of analytical, numerical and experimental approaches
}

PLEASE CITE THE PUBLISHED VERSION

http://dx.doi.org/10.1260/026309206778494300

PUBLISHER

(C) Multi-Science Publishing

VERSION

VoR (Version of Record)

LICENCE

CC BY-NC-ND 4.0

REPOSITORY RECORD

Georgiev, Vasil B., Victor V. Krylov, and Edward Winward. 2012. "Simplified Modelling of Vehicle Interior Noise: Comparison of Analytical, Numerical and Experimental Approaches”. figshare.

https://hdl.handle.net/2134/10306. 
This item was submitted to Loughborough's Institutional Repository (https://dspace.lboro.ac.uk/) by the author and is made available under the following Creative Commons Licence conditions.

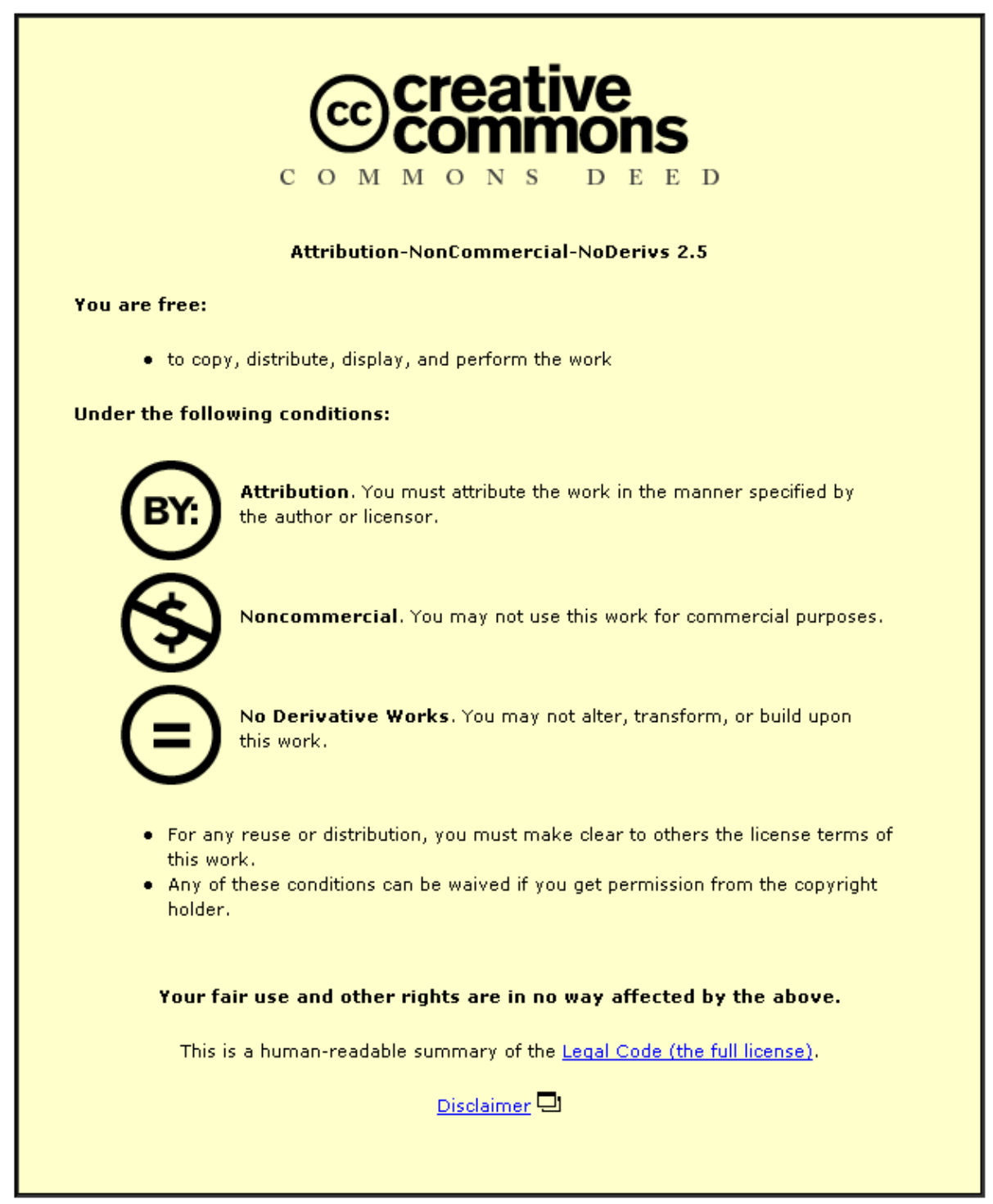

For the full text of this licence, please go to: http://creativecommons.org/licenses/by-nc-nd/2.5/ 


\title{
Simplified Modelling of Vehicle Interior Noise: Comparison of Analytical, Numerical and Experimental Approaches
}

\author{
V.B. Georgiev, V.V. Krylov and R.E.T.B. Winward \\ Department of Aeronautical and Automotive Engineering, \\ Loughborough University, \\ Loughborough,Leicestershire, LEII 3TU, UK
}

Received 23th April 2006

\begin{abstract}
The present paper describes the results of the investigation of low and medium frequency vehicle interior noise carried out using simplified structural-acoustic models. Analytical, finite element (FE) and experimental studies are presented and compared. In particular, the analytical approach is based on the formula representing the interior acoustic pressure in terms of structural and acoustic normal modes. This procedure does not take into account the effect of the enclosed air on structural vibrations. The FE analysis considers structural vibration modes, interior acoustic modes, full structural-acoustic interaction and the resulting structure-borne noise. The above-mentioned analytical and numerical results are compared with each other, and both of them are compared with the experimental results obtained for the simplified reduced-scale vehicle model "QUASICAR" developed in Loughborough University. The comparisons demonstrate some specific features of the analytical and numerical approaches and outline the acceptable limits of simplification in modelling vehicle interior noise. Although this study is concerned with structure-borne vehicle interior noise, its results and conclusions could be of interest for a wider range of engineering problems, such as building acoustics and dynamics of thin shell structures.
\end{abstract}

\section{INTRODUCTION}

Interior noise is an important issue for many industries, including the automotive and aeronautical ones. To reduce time and effort required for analyzing and mitigating vehicle interior noise it is preferable to undertake most of the associated work at the design stage. Thus, virtual simulations and predictive methods become increasingly attractive in studying interior noise. They form an integral part of the design and development process as mitigation of intrusive noise leads directly to the enhancement of consumers' perception of product quality [1]. In particular, for the automotive industry, the tuning of vehicles' acoustical properties to convey distinct characteristics of the brand, especially in the low-frequency range, should be considered as an additional motivation for analysing interior noise at this stage [2].

The mechanisms and sources of vehicle interior noise can be different. In the low and medium frequency range, the most important contribution comes from structure-borne noise. If a structure of a vehicle vibrates, then its vibration radiates sound into the interior as well as into the exterior. In turn, the vibrations of vehicle structures can be caused by different sources, including engine and transmission systems, tyre/road interaction, and aerodynamic forces, the latter being important at high vehicle speeds and at higher frequencies [3]. Obviously, the generated interior noise is dependent not only on the above-mentioned sources of structural vibrations, but also on the vibration characteristics of car body structures and on the acoustic 
properties of the passenger compartments.

The coupling between structural vibrations and air pressure fluctuations in the interior is a distinctive attribute of interior noise. Because of the energy exchange between the acoustic and structural sub-systems of a fully coupled model, the dynamic behaviour of each of these sub-systems is influenced by the behaviour of the other [4-7]. In other words, the interaction or coupling between air and body structure alters their dynamic characteristics, and thus determines the complexity of interior noise analysis in some particular cases. However, in many practical situations the effect of the enclosed air on structural vibrations can be disregarded and the structural-acoustic analysis can be simplified very substantially [8-9].

The analysis of structure-borne interior noise can be carried out using different approaches. For a limited number of structures with simple geometry, one can use analytical solutions to structural-acoustic problems. This provides a great opportunity for an explicit physical interpretation and understanding of the cases considered. The most popular analytical model considered so far represents a rigid rectangular box with one flexible wall. Lyon was the first to have used this model for calculating noise reduction in low- and high-frequency ranges using energy methods [10]. Later, Pretlove has obtained the exact solution for acoustic velocity potential in terms of infinite Fourier series for free [8] and forced [9] vibrations of the flexible wall. For estimating the coupling between the acoustic modes of an enclosure and the vibratory motion of the surrounding structure a dimensionless quantity called joint acceptance function was established [11,12].

In contrast to the above-mentioned case of a rigid box structure with one flexible wall, the analysis of irregular cavities, such as real car compartments, still challenges researchers and requires specific investigations. Moreover, there are in general around 700 structural and 25 acoustic modes in the range $0-300 \mathrm{~Hz}$ for a typical passenger car structure and compartment respectively [13]. Thus, a full treatment of the problem analytically is an extremely cumbersome if not impossible task.

The inability of obtaining reliable analytical solutions for complex vehicle structures leads to alternative either experimental or numerical approaches in the treatment of the problem. The conventional numerical approach for predicting interior noise across the entire frequency range relies upon the synthesis of different modelling techniques. In the low frequency range, $10-250 \mathrm{~Hz}$, the most common techniques are the Finite Element Method (FEM) and the Boundary Element Method (BEM), as the upper limit reported in literature is about $500 \mathrm{~Hz}$ [14]. In the high frequency range, above $500 \mathrm{~Hz}$, Statistical Energy Analysis (SEA) is used widely. The application of FEM to vehicle interior noise problems can be traced back to the 1970's when Petyt at al. [15] proposed a twenty-node iso-parametric finite element for analysing irregular shaped cavities. The limited computational resources at that time induced the use of a two-dimensional formulation of FEM also called simplified FEM [16].

After making it possible to simulate the acoustic domain of vehicle compartments,attention has turned to a complete strategy for interior noise reduction at a design stage. The first work of this kind carried out by Nefske et al. [17] presented a model for computing acoustic modes and interior noise levels using FEM, when structural characteristics and exiting forces were known. At a later stage, Sung and Nefske [18] predicted vehicle interior noise and identified noise sources for the coupled system 'vehicle structure - acoustic interior'. The interior acoustic response was determined using a modal solution procedure. Moreover, the analysis was carried out to identify structural and acoustic modal participation as well as the boundary panel participation in producing the response. These investigations have become a milestone in vehicle interior noise studies.

The principal drawback associated with finite element modeling of vehicle interior noise is the necessary compromise between finite element size and accuracy. The existing full vehicle vibro-acoustic models have more than I million degrees of freedom $[19,20]$ and consequentially they take a long time to be developed and solved. In this regard, BEM can be considered as a useful alternative 
to FEM because it reduces the dimensions of s problem via the boundary surface integral representation. Thus, the final system of equations is much smaller than an equivalent FEM model. However, with BEM the coefficient matrix is fully populated and is non-symmetric [21], and this can result in BEM being slower. Therefore, the numerical advantage of one of these methods over the other is quite arguable.

In the high frequency range, SEA is an established technique for interior noise analysis. The technique was developed in the 1960's by Lyon [22] for the prediction of structure-borne noise and vibration of complex space flight structures. SEA involves the division of a vehicle into various sub-systems from which energy can be lost through internal dissipation (internal loss factor) and through coupling with other sub-systems in the assembly (coupling loss factor). SEA is a mature technique and is applicable to investigating vehicle interior noise abatement during the design stage. However, a complete structural-acoustic trimmed SEA vehicle model can include 400-500 sub-systems and full size models can prove to be difficult to describe [23].

Although the above-mentioned numerical methods have achieved satisfactory levels of accuracy in predicting interior structural-acoustic response, they are not very helpful in understanding the physical mechanisms behind the problem that could assist in predicting the behaviour of similar but slightly modified structures. Therefore, there remains the scope for further development of the theory to assist in a better understanding the physics of structure-borne interior noise, especially its dependence on different parameters of vehicle structures and interior cavities. In this case, a simplification of structural and acoustic models could be an attractive option to study the mechanisms of structure-borne interior noise and to assist in better understanding the results of vibro-acoustic analysis.

Note that the use of simplified and reduced scale models for theoretical and experimental investigations of structure-borne interior noise has been described in several papers. As was mentioned above, such models are useful for understanding the physics of the problem and for simulation of the main features of a structuralacoustic system responsible for noise generation. In particular, purely acoustic experiments have been conducted on scale replicas of vehicle interiors with walls described by rigid boundary conditions [3, 24-27]. In the examples described by Jha [3] and Lee et. al. [24], the model was a 1:2 scale replica of the passenger compartment of a saloon car, whereas Nakanishi [25] studied the acoustic properties of a 1:4.5 scale cavity that simulated a truck cab. Schroeder [26] and Gorman et. al. [27] simplified their models to equivalent rectangular cavities having the same volume as the actual enclosure in order to calculate the acoustic response. Combined structural-acoustic analysis of 1:2 scale simplified models resembling real vehicles have been carried out by Kim et. al. [7], Song et. al. [6], and Park et. al. [28]. Most recently, the well known structural-acoustic model - rectangular cavity with one vibrating wall was investigated again to demonstrate a new hybrid method for simulating the so-called 'boom noise' and identifying the parameters that affect its generation [29].

In addition to the above, some types of simplified models could be useful for studying vehicle interior noise analytically. One of the present authors (Krylov) has developed such an approach in respect of rather general simplified vehicle structures [30]. The results of this approach can be expressed in terms of analytical formulae for sound pressure in the model interior as a function of road irregularity, vehicle speed, properties of suspension, and the normal modes of structural and acoustic subsystems. Later on, the above-mentioned analytical results have been compared with the experimental ones [31] obtained for a reduced-scale physical model called QUASICAR (QUArter Scale Interior Cavity Acoustic Rig), see Fig. 1.

The present study is the continuation of the above-mentioned papers [30, 31]. It aims to compare the results of the investigations of structure-borne interior noise in the QUASICAR model carried out by three different approaches: analytical, numerical and experimental. The main attention is paid to presenting the details of the finite element structural-acoustic analysis in the QUASICAR model as well as 
in its modification and to comparison of the obtained results with the analytical and experimental ones. Moreover, the study endeavours to find out to what extent physical models can be simplified, so that one could use analytical formula for vehicle interior noise. Although this study is concerned with structure-borne vehicle interior noise, its results and conclusions could be of interest for a wider range of engineering problems, such as building acoustics and dynamics of thin shell structures.

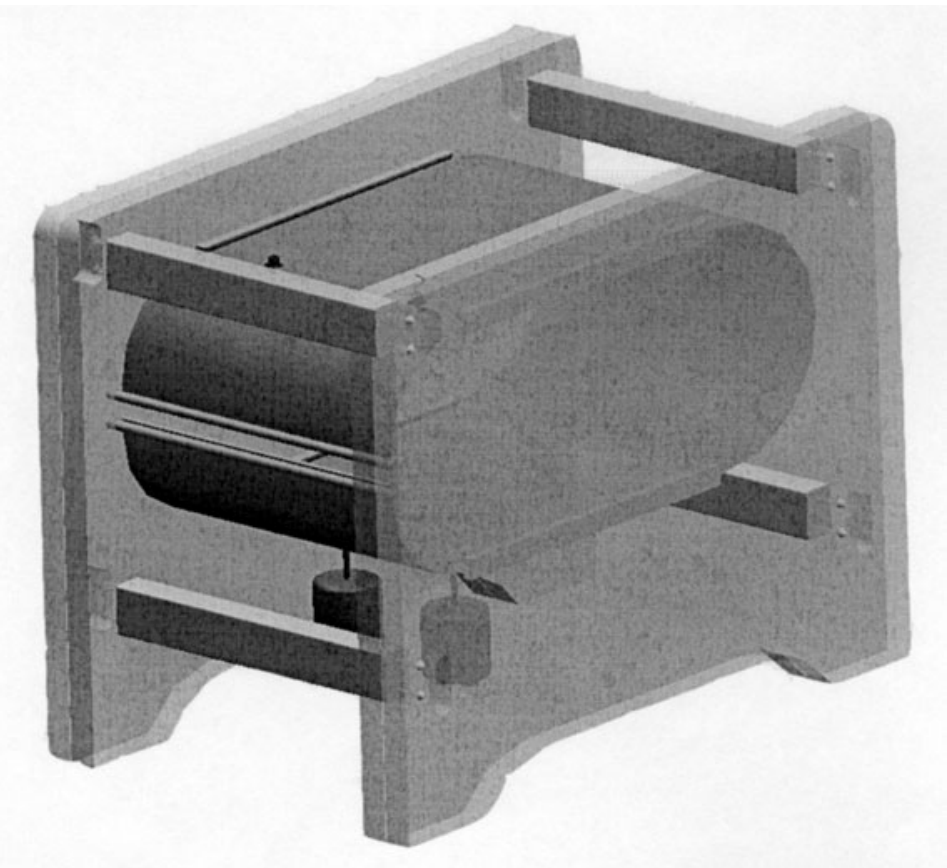

Figure l: $\quad 3 D$ model of the QUASICAR test rig.

\section{THEORETICAL CONSIDERATIONS}

It has been shown in the paper [30] that the acoustic pressure of structure-borne sound in the interior can be expressed in the form: (see list of terms at the end of the text)

$$
p(\mathbf{r})=\frac{4 c^{2} \rho_{a} P}{\omega^{2} \rho_{s} h_{s} V} \sum_{m=0}^{\infty} \sum_{p=1}^{\infty} a_{m} F_{m p}(\omega) S_{m p} \Phi_{m}(\mathbf{r}) \Psi_{p}(\rho),
$$

where

$$
F_{m p}(\omega)=\frac{\omega^{4}}{\left(\omega_{m}^{2}-\omega^{2}-2 i \delta_{m} \omega\right)\left(\omega_{p}^{2}-\omega^{2}-2 i \delta_{p} \omega\right)}
$$

and

$$
\mathrm{S}_{\mathrm{mp}}=\frac{1}{\left(\mathrm{~L}_{\mathrm{x}_{1}}-\mathrm{L}_{\mathrm{x}_{0}}\right) \mathrm{L}_{\mathrm{y}}} \int_{0}^{\mathrm{Ly}} \int_{\mathrm{L}_{\mathrm{x}_{0}}}^{\mathrm{L}_{\mathrm{x}_{1}}} \Phi_{\mathrm{m}}(\mathrm{x}, \mathrm{y}) \Psi_{\mathrm{p}}(\mathrm{x}, \mathrm{y}) \mathrm{dxdy}
$$

In what follows we shall apply Eqns. (1)-(3) to the simplified reduced-scale model QUASICAR mentioned in the Introduction (see Figs. 1 and 2). 


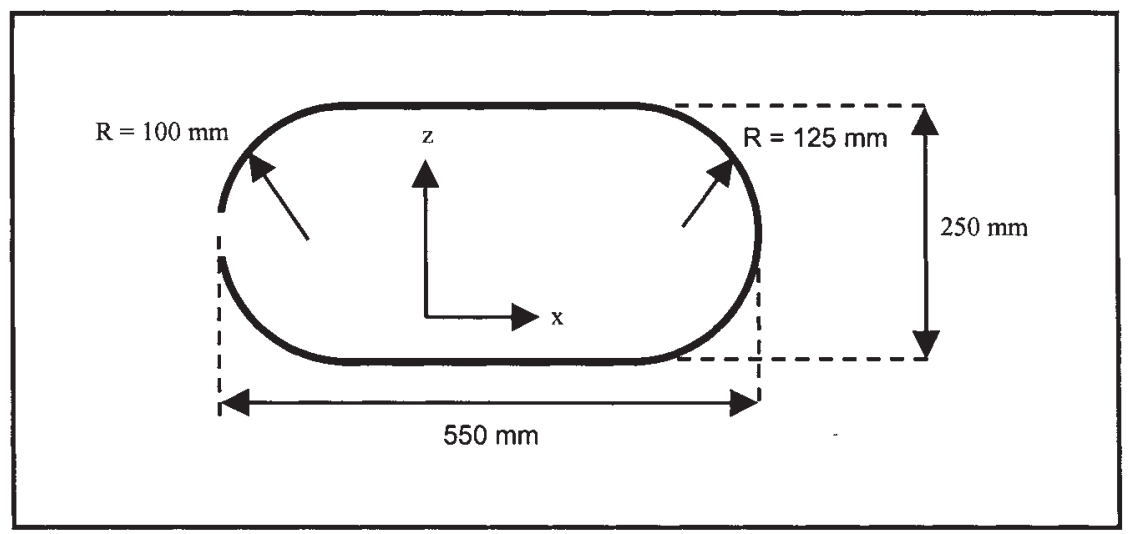

Figure 2: QUASICAR geometry.

To simplify the analysis of the acoustic modes of the QUASICAR we approximate its interior acoustic cavity as the equivalent rectangular box having the same volume $\mathrm{V}$. Thus, the dimensions of the equivalent rectangular box are $\mathrm{L}_{\mathrm{x} \text { eq }}$ along the $\mathrm{X}$-axis, whereas $\mathrm{L}_{\mathrm{y}}$ and $\mathrm{L}_{\mathrm{z}}$ are the same.

As it has been mentioned in one of our previous papers [32], the structural modes of the non-circular cylindrical shell representing the QUASICAR flexible structure are symmetric and anti-symmetric ones, with almost equal resonant frequencies. This means that, if an external force is applied to top or bottom part of the shell, both symmetric and anti-symmetric modes are excited with equal amplitudes. Thus, the combination of these modes results in fact that only the part to which the force is applied is vibrating, whereas the opposite side has zero amplitude. This can be interpreted as if only one side of the shell is excited - the one to which the external force is applied. Also, it has been taken into account that vibrations of QUASICAR's curved parts are negligibly small in the frequency range considered due to the shell's mode shapes, as it will be shown in more detail in section 5.1. Therefore, one can approximate the contribution of the whole non-circular shell by the contribution of its single quasi-flat part to which the external force is applied.

The parameters used in Eqs. (1)-(3) are as follows: $P=10 \mathrm{~N}$ is the amplitude of a harmonic force applied to the flexible wall, $\mathrm{c}=343 \mathrm{~m} / \mathrm{s}$ and $\rho_{\mathrm{a}}=1.29 \mathrm{~kg} / \mathrm{m}^{3}$ are the sound velocity and mass density of air, $\mathrm{h}_{\mathrm{s}}=0.0012 \mathrm{~m}$ and $\rho_{\mathrm{s}}=7950 \mathrm{~kg} / \mathrm{m}^{3}$ are the thickness and mass density of the non-circular cylindrical shell, $\mathrm{L}_{\mathrm{x} \text { eq }}=0.506 \mathrm{~m}, \mathrm{~L}_{\mathrm{y}}$ $=0.3 \mathrm{~m}$, and $\mathrm{L}_{\mathrm{z}}=0.25 \mathrm{~m}$ are the geometrical dimensions of the equivalent QUASICAR interior, $\mathrm{L}_{\mathrm{x} 1}=0.425$ and $\mathrm{L}_{\mathrm{X} 0}=0.1 \mathrm{~m}$, are the boundary coordinates in $\mathrm{X}$ direction of the vibrating quasi-flat flexible wall, $\phi_{\mathrm{m}}$ and $\psi_{\mathrm{p}}$ are the modal shapes of acoustic and structural modes respectively, $\delta_{\mathrm{m}}=\omega_{\mathrm{m}} / 100$ and $\delta_{\mathrm{p}}=\omega_{\mathrm{p}} 3 / 100$ are their attenuation decrements, and $a_{m}$ are the coefficients depending on the acoustic mode type and on the shape of the enclosure.

Note that Eqn. (1) can be considered as consisting of three important terms which contribute most to the overall acoustic pressure. The first one is the function before the summation, which is inversely proportional to the square of driving frequency $\omega$. This function decreases with increasing the frequency and outlines the overall behaviour of the acoustic response. However, if disturbing forces are dependent on the second or even on the third power of frequency, such as aerodynamic forces, then the overall trend of pressure acoustic response might get higher when the frequency is increased. In case of harmonic external force, as in Eqn. (1), the plate thickness, $h_{s}$ and the enclosed volume, $\mathrm{V}$ can influence the speed of the function's diminution. Obviously, the bigger the cavities and the thicker walls, the faster is function's diminution.

The non-dimensional function $\mathrm{F}_{\mathrm{mp}}(\omega)$ defined by Eqn. (2) can be called the 'frequency overlap function' of the acoustical and structural modes characterised by overall indexes $\mathrm{m}$ and $\mathrm{p}$ [30]. It can be considered as a time filtration function - only those natural structural $\omega_{\mathrm{p}}$ and acoustic $\omega_{\mathrm{m}}$ frequencies which coincide with the 
driving frequency $\omega$ contribute most to the acoustic pressure response. This can be seen clearly in Fig. 3 showing the function $\mathrm{F}_{\mathrm{mp}}(\omega)$ calculated for 50 structural and acoustic natural frequencies in the interval from 1 to $50 \mathrm{rad} / \mathrm{s}$, and for a driving frequency $\omega$ equal to $35 \mathrm{rad} / \mathrm{s}$. The maximum peak of the function takes place when the structural, acoustic and driving frequencies coincide at $35 \mathrm{rad} / \mathrm{s}$. In this case structural and acoustic parts act as amplifiers, thus increasing the disturbing force. In vehicles this phenomenon is known as the 'boom noise effect'.

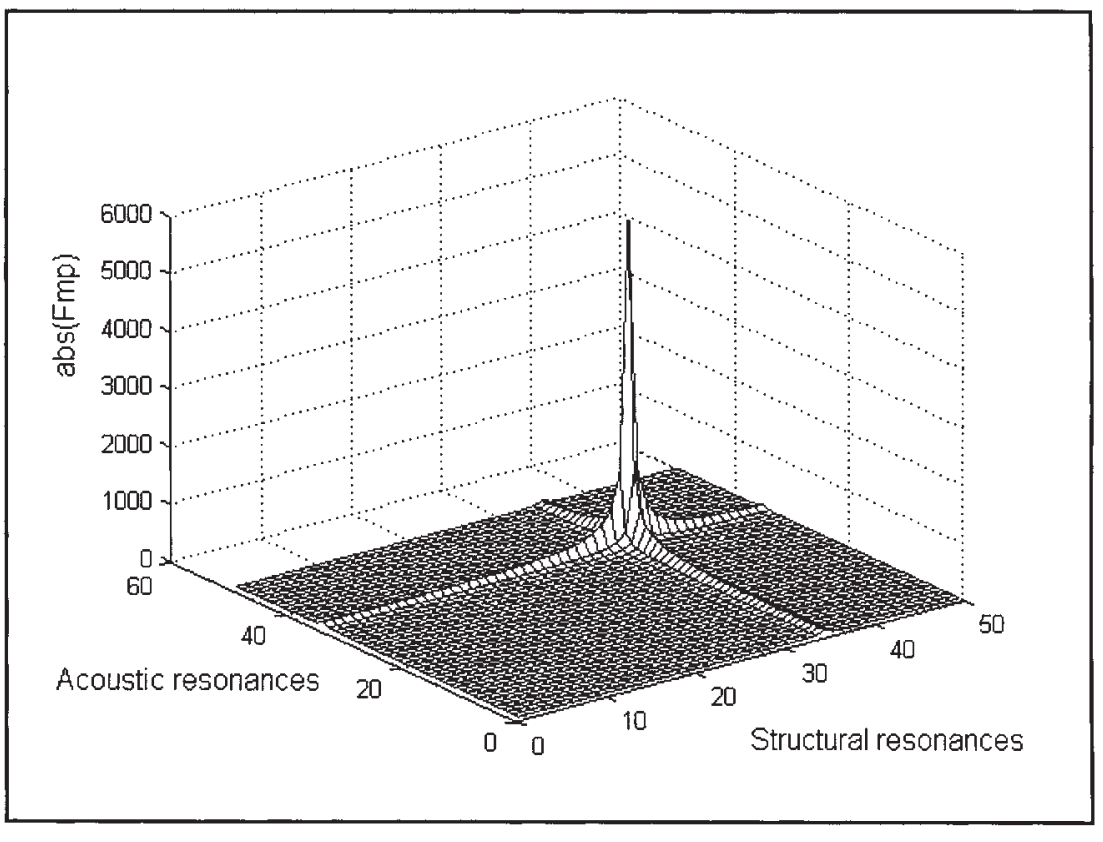

Figure 3: $\quad$ Magnitude of the function $\mathrm{F}_{\mathrm{mp}}$.

The non-dimensional factor $S_{m p}$ defined by Eqn. (3) represents the corresponding coefficients of spatial coupling between acoustic and structural modes. Therefore, it can be called the 'coefficient of structural-acoustic coupling'. It can be considered as a space filtration function - the higher values of the coupling coefficients are associated with the spatial similarity between structural and acoustic modal shapes. Note that these coefficients are not directly related either to the driving frequency or to the acoustic or structural resonant frequencies. They depend only on geometrical coincidence between acoustic and structural modal shapes on the walls. Figure 4 shows the magnitudes of the coupling coefficients between the first 10 acoustic and 30 structural modes. Some of the coefficients, for example: $\mathrm{S}_{1,3}, \mathrm{~S}_{4,3}, \mathrm{~S}_{5,3}, \mathrm{~S}_{6,3}, \mathrm{~S}_{10,3}$, $\mathrm{S}_{10,6}$ or $\mathrm{S}_{4,6}$, show larger values compared to the others. This means that the first, fourth, fifth, sixth and tenth acoustic modes are geometrically well coupled to the third and sixth structural modes. Overall, however, because of the double filtration, over time and space described by the products $\mathrm{F}_{\mathrm{mp}}(\omega) \mathrm{S}_{\mathrm{mp}}$, only a few of the structural and acoustic modes interact effectively and give noticeable contributions to the acoustic pressure response.

Before carrying out the above-mentioned analytical calculations for the QUASICAR model, which will be discussed in section 5.5, it is instructive for validating purposes to compare the analytical and numerical procedures used herein for the simplest structural acoustic model - a rigid rectangular box with one flexible wall (see Fig. 5) having the following dimensions: $\mathrm{L}_{\mathrm{x}}=1.0 \mathrm{~m}, \mathrm{~L}_{\mathrm{y}}=0.6 \mathrm{~m}$ and $\mathrm{L}_{\mathrm{z}}=$ $0.5 \mathrm{~m}$. Two pressure frequency response functions (FRF's) have been calculated for such a model. The first FRF has been calculated analytically using Eqn. (1), where integration over $x$ in Eqn. (3) took place from 0 to $\mathrm{L}_{\mathrm{x}}$. The second FRF has been calculated using finite element simulation of the same model. An external force was applied at a point on the flexible panel with coordinates $\mathrm{x}_{\mathrm{p}}=0.3 \mathrm{~m}$ and $\mathrm{y}_{\mathrm{p}}=0.2 \mathrm{~m}$ and a receiver point for acoustic pressure has been chosen randomly, with the coordinates $\mathrm{x}_{\mathrm{r}}=0.7 \mathrm{~m}, \mathrm{Y}_{\mathrm{r}}=0.4 \mathrm{~m}$ and $\mathrm{Z}_{\mathrm{r}}=0.4 \mathrm{~m}$. 


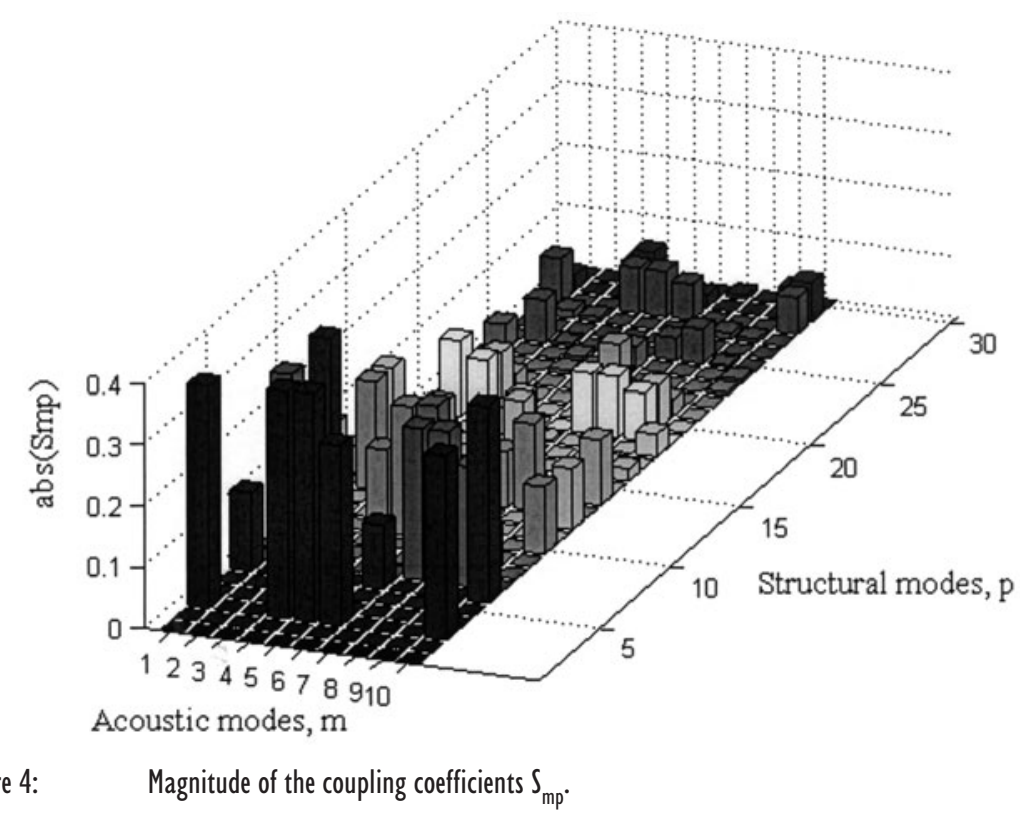

One can see that the analytical and numerical curves shown in Fig. 5 agree very well with each other. The coincidence of these two curves thus validates the analytical and numerical approaches used in the present study. Note that Eqn. (1) does not take into account the effect of the enclosed air on vibrations of the surrounding structure, whereas finite element simulations automatically take into account the full coupling between the air and the structure. The observed good agreement of these results shows that the air loading can be neglected in the case considered because the values of air's and steel's stiffness in this particular case are considerably dissimilar, as it was pointed out in [8]. A noticeable disagreement can be observed in the area of the first resonant peak, due to a strong coupling of the structural modes and the first (zero-order) acoustic mode which has been neglected in the analytical formula, as was mentioned above.

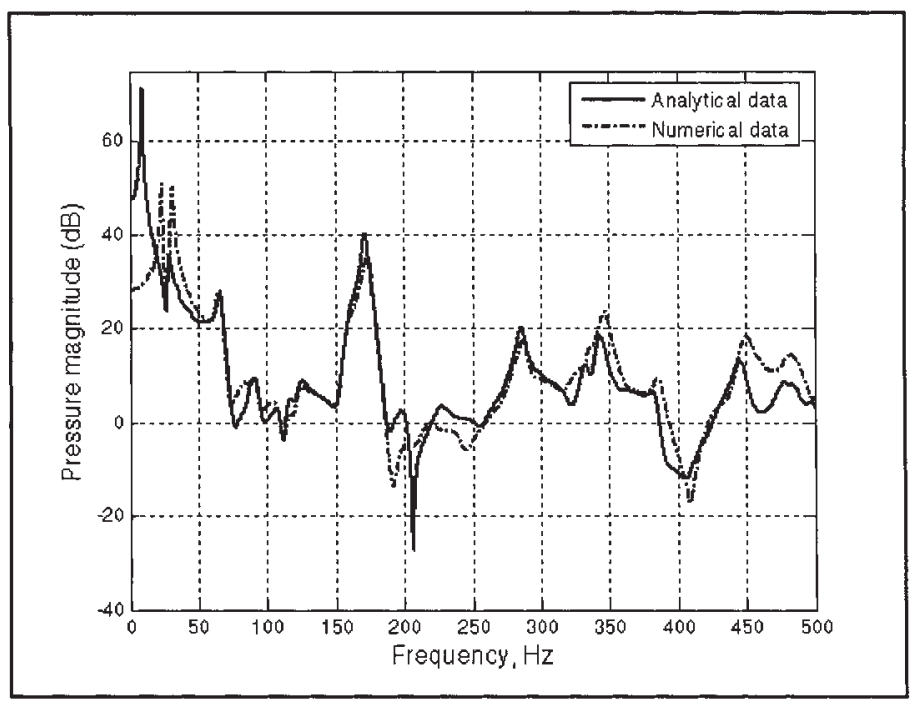

Figure 5: Comparison of the analytical (solid curve) and numerical (dash-dotted curve) results for the frequency response function (FRF) of the rigid rectangular box with one flexible wall.

\section{NUMERICAL SIMULATIONS}

The numerical part of this investigation includes an independent finite element (FE) analysis of the structural and acoustic parts of the simplified model, and a coupled 
structural-acoustic analysis with and without external disturbing force, respectively. Moreover, additional calculations have been carried out to consider a slightly modified vehicle model characterised by a different thickness of the bottom plate. As in the previous section, the basic model represents a non-circular cylindrical shell made of a single curved steel plate of $1.2 \mathrm{~mm}$ thickness, as shown in Fig. 6, whereas in the modified model the bottom part (plate A) has a thickness of $6 \mathrm{~mm}$. The above-mentioned QUASICAR's shell was attached to massive wooden sidewalls (see Fig. 1) supplied with beads implementing simply supported boundary conditions [31].

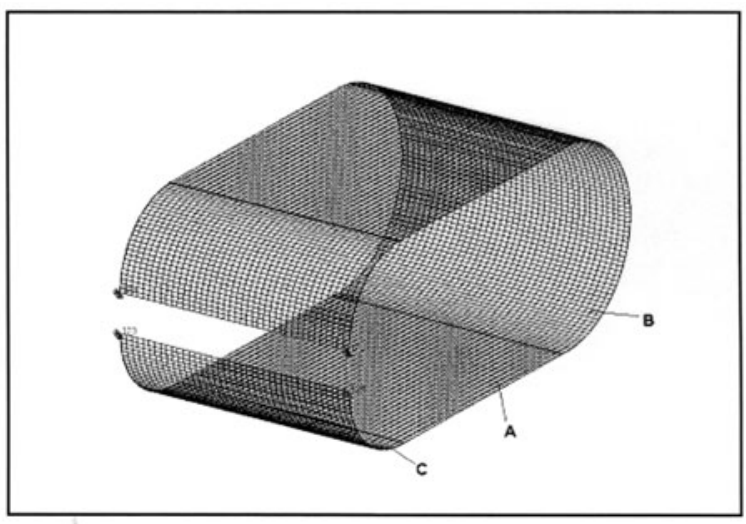

Figure 6: $\quad$ Structural finite element model.

FE analysis of the independent structural part has been performed for the first 30 natural frequencies of the model under consideration. For validation purposes, FE calculations have been carried out also for a simply supported rectangular plate with the same dimensions like plate A (see Fig. 6). The FE model of the curved plate had in total 68101 nodes and 67500 isomesh CQUAD4 surface elements, and the FE model of the rectangular plate consisted of 12221 nodes and 12000 isomesh CQUAD4 surface elements.

Similarly to the structural part, FE analysis of the independent acoustic interior has been performed for the first 30 normal modes. The acoustic cavity was modelled by 1970 CHEXA acoustic elements (Fig. 7) and 2464 acoustic nodes, with pressure as a degree of freedom. For the FE calculations the following physical parameters of the air have been used: $\rho=1.2 \mathrm{kgm}^{-3}$ and $c=343 \mathrm{~ms}^{-1}$, and the mesh size was consistent with the wavelength $\lambda=c / f_{i j, k}=0.343 \mathrm{~m}$ at the highest frequency of interest.

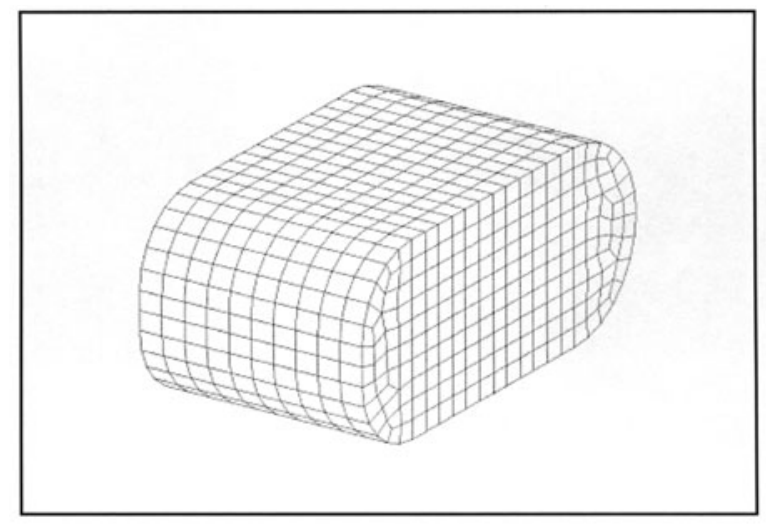

Figure 7: $\quad$ Acoustic finite element model.

In the case of coupling between acoustic and structural part being taken into account, the discretisation of the acoustic field in finite elements leads to the following equations for sound pressure [17]: 


$$
\left[\mathbf{M}^{a}\right]\{\ddot{\mathbf{p}}\}+\left[\mathbf{K}^{a}\right]\{\mathbf{p}\}=\{\mathbf{I}\}
$$

Here $\{\mathbf{p}\}$ is vector of the $m$ nodal sound pressure at each air point; $\left[\mathbf{M}^{a}\right]$ and $\left[\mathbf{K}^{a}\right]$ are the $m \times m$ acoustic mass and stiffness matrices, and $\{\mathbf{I}\}$ is the vector of normalised forces induced by structural displacements $\left[\mathrm{kg}^{2} /\left(\mathrm{m} \mathrm{s}^{4}\right)\right]$, i.e. time derivatives of actual forces multiplied by $\rho c$. In the absence of external forces, the structural equation of motion taking into account structural-acoustic interaction can be written as follows:

$$
\left[\mathbf{M}^{s}\{\ddot{\mathbf{v}}\}+\left[\mathbf{K}^{s}\right]\{\mathbf{v}\}=[\mathbf{S}] \mathbf{p}^{b}\right\}
$$

where $\{\mathbf{v}\}$ is vector of the $n$ structural displacements, $\left[\mathbf{M}^{s}\right]$ and $\left[\mathbf{K}^{s}\right]$ are the $n x n$ structural mass and stiffness matrices, $\left\{\mathbf{p}^{b}\right\}$ is vector of sound pressures at the boundary grid points, and $[\mathbf{S}]$ is a sparse $n \times m$ structural-acoustic coupling matrix which elements are determined from the surface area $S_{i j}$ for the boundary grid point corresponding to the structural displacement $v_{i}$ and the associated sound pressure at that point $p_{j}$. For the sake of simplicity, the governing equations of the acoustic and structural parts, respectively, Eqs. (4) and (5), have been written with the damping matrix being ignored.

If external disturbing forces are applied to the structure then the whole set of the governing equations of the structural-acoustic coupling model can be written in the following form:

$$
\left[\begin{array}{cc}
{\left[\mathbf{M}^{s}\right]} \\
{\left[\mathbf{M}^{a s}\right]}
\end{array}\right]\left[\begin{array}{l}
{[0]} \\
{\left[\mathbf{M}^{a}\right.}
\end{array}\right]\left\{\left\{\begin{array}{l}
\{\ddot{\mathbf{v}}\} \\
\ddot{\mathbf{p}}\}
\end{array}\right\}+\left[\begin{array}{cc}
{\left[\mathbf{K}^{s}\right]} & {\left[\mathbf{K}^{s a}\right.} \\
{[0]} & {\left[\mathbf{K}^{a}\right.}
\end{array}\right]\right]\left\{\begin{array}{l}
\{\mathbf{v}\} \\
\{\mathbf{p}\}
\end{array}\right\}=\left\{\begin{array}{c}
\{\mathbf{F}\} \\
0
\end{array}\right\} .
$$

where $\left[\mathbf{M}^{a s}\right]=\rho^{2} c^{2}[\mathbf{S}]^{T},\left[\mathbf{K}^{s a}\right]=-[\mathbf{S}]$, and $\{\mathbf{F}\}$ is the vector of disturbing dynamic forces. Solving this equation, one can obtain the structural displacements and the interior sound pressure due to a certain disturbance in a coupled structural-acoustic model. For free vibration analysis the vector of disturbing forces should be equalised to zero.

Using FEM, a frequency response analysis for sound pressure was performed in the range from 0 to $500 \mathrm{~Hz}$. On the bottom flat part of the simplified model QUASICAR and of the modified model $\boldsymbol{M l}$ a harmonic force was applied. The interior sound pressure at the driver's ear location (acoustic node 400) and at the place corresponding to the passenger's (seating behind the driver) ear location (acoustic node 409) were calculated. Only structural damping has been taken into account in these computations. The acoustic medium was considered as ideal.

\section{EXPERIMENTAL TESTING}

All experimental measurements of structural vibrations, acoustic modes and structure-borne interior noise have been carried out in the Noise and Vibration Laboratory at the Department of Aeronautical and Automotive Engineering at Loughborough University. The measurement data were recorded using a HP 3566 FFT analyzer. For measurements of structural frequency responses a Bruel\&Kjaer Type 4347 accelerometer was used, and for measurements of modal spatial patterns a pair of PCB Piezotronics Type 352M24 ICP accelerometers was employed. The excitation signal, a continuous white noise, was generated by the HP 3566 FFT analyzer and transmitted to a Ling Dynamic Systems 200 series electromagnet shaker. For acoustic frequency response measurements both a Bruel\&Kjaer Type 2230 SPL meter and a Bruel\&Kjaer 1/2 inch condenser microphone were used. And for measurements of acoustic modal patterns a small 1/4 inch G.R.A.S. Type 40BD Prepolarised Pressure Microphone was employed. The excitation signal, a 
continuous white noise generated by the HP 3566 FFT analyzer, was applied to a miniature Visaton medium range loudspeaker.

\section{RESULTS AND DISCUSSIONS}

\section{I Independent structural analysis of QUASICAR}

First of all, let us note that QUASICAR structure can be considered as a combination of simple structures: plates A and shells B and C (see Fig. 6). Table I shows the natural frequencies of the simply supported rectangular plate having the same dimensions as the QUASICAR flat sides A (Columns 1,2) and of the whole QUASICAR model (Columns 4, 5). The corresponding spatial patterns are shown in Fig. 8. Obviously, the two plates A of the QUASICAR have the lowest stiffness and consequently the lowest fundamental frequency in the whole combination. The analysis shows that the first resonant peak of the two plates $\mathrm{A}$ is at $67.035 \mathrm{~Hz}$ (67.039 Hz- for anti-symmetric mode, see Fig. 9), the half of a circular shell B $906.04 \mathrm{~Hz}$, and the two quarters of a circular shell C - $1271.40 \mathrm{~Hz}$. Bearing in mind the low-frequency range of interest for this research (up to $1000 \mathrm{~Hz}$ - corresponding to $250 \mathrm{~Hz}$ for a real vehicle) and noticing that resonant frequencies of curved parts are above $900 \mathrm{~Hz}$, it is reasonable to approximate the normal modes of QUASICAR by the normal modes of a simply supported rectangular plate having the dimensions of the QUASICAR flat sides (see Fig. 8).

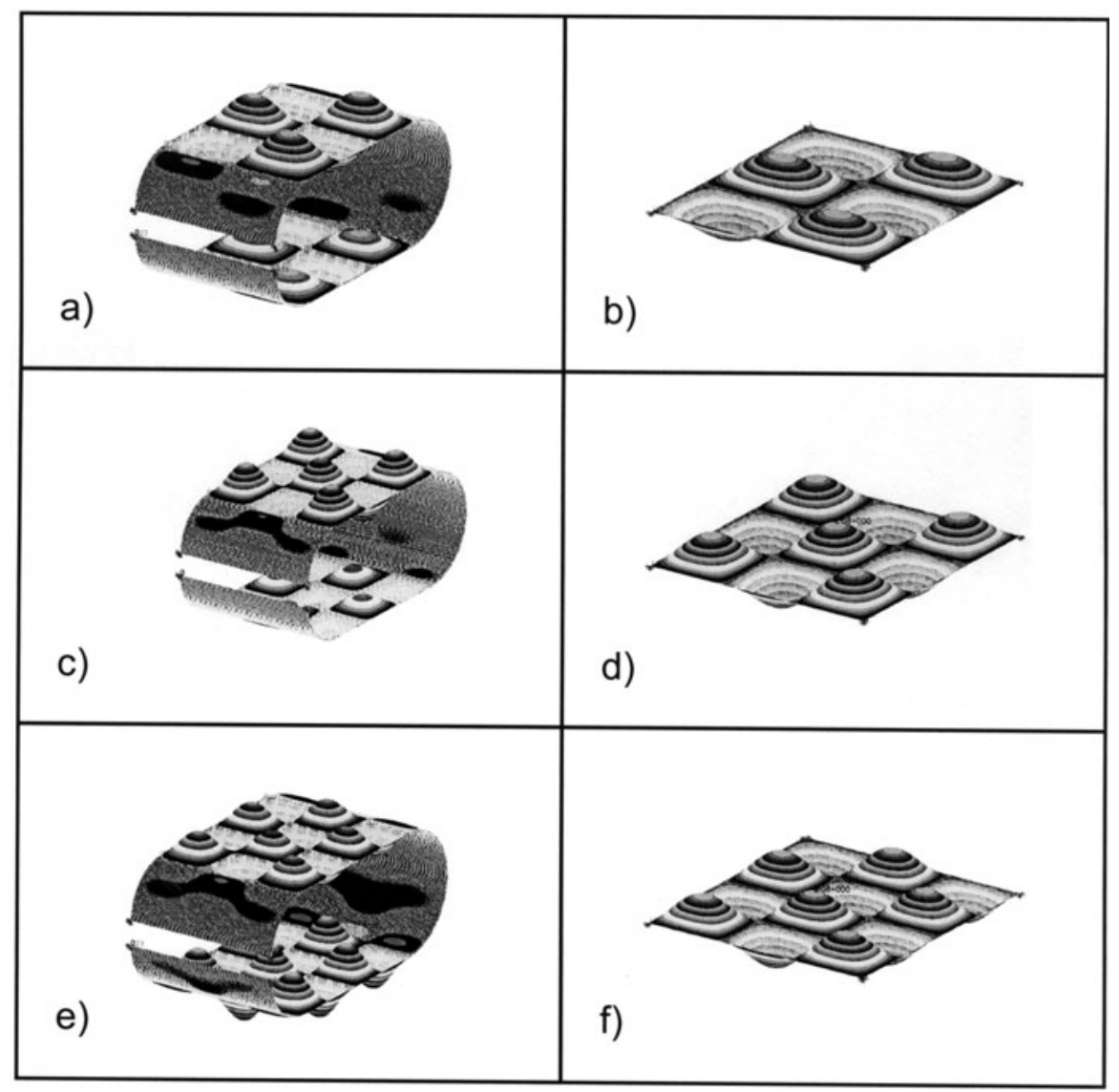

Figure 8: $\quad$ Higher-order structural modes of QUASICAR: a) $364.4 \mathrm{~Hz}$, c) $521.45 \mathrm{~Hz}$, e) $691.68 \mathrm{~Hz}$, and of a simply supported rectangular plate: b) $372.62 \mathrm{~Hz}$, d) $531.95 \mathrm{~Hz}$ and f) $721.99 \mathrm{~Hz}$. 


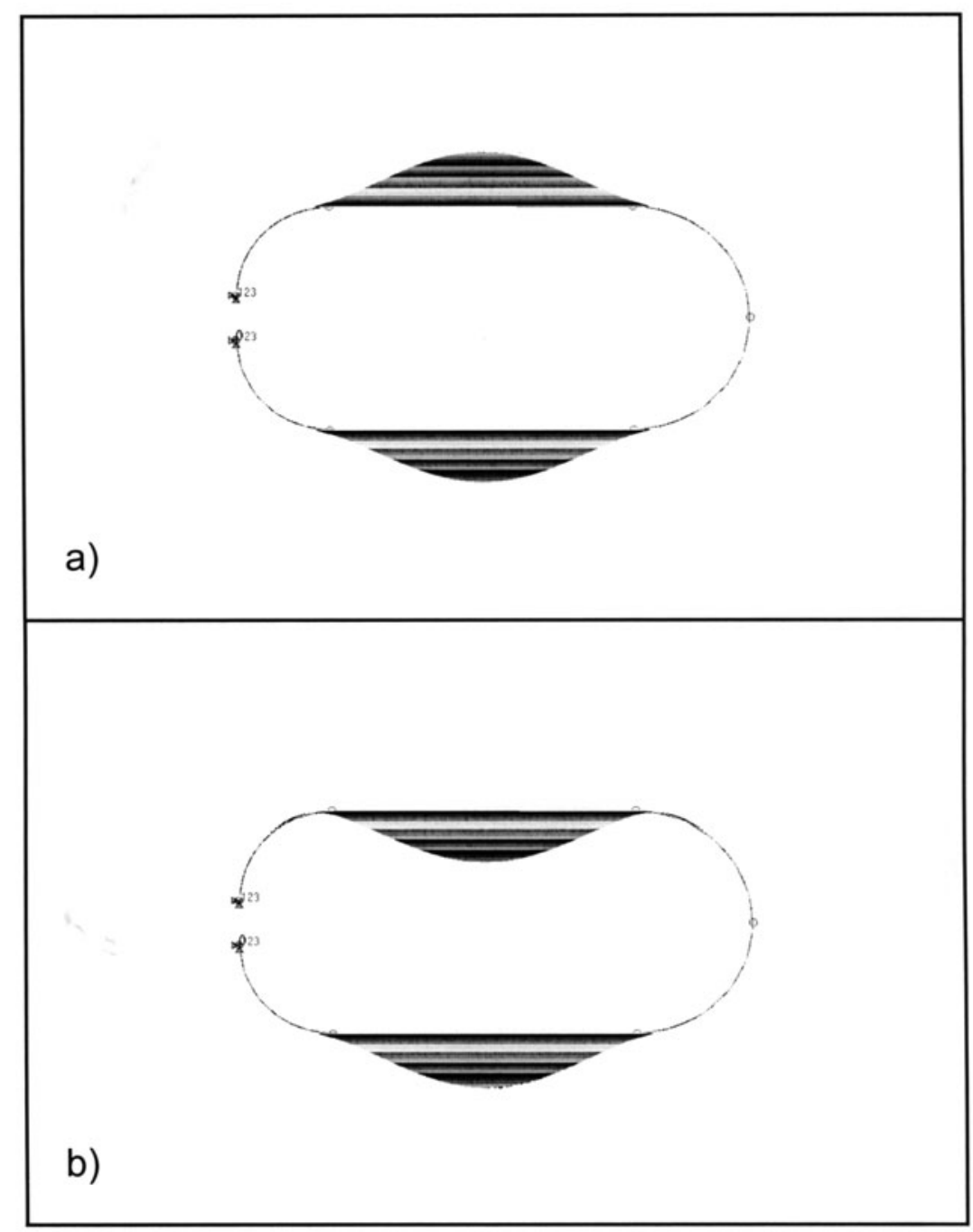

Figure 9: $\quad$ Lowest-order symmetric (a) and anti-symmetric (b) normal modes of QUASICAR

Resonant frequencies of the QUASICAR structure and of the uncoupled flat plates A agree well in the frequency range considered. The results show that the natural frequencies of the coupled model (QUASICAR structure) are higher for the first four normal modes and lower for the rest of the modes, as compared to the resonant peaks of the uncoupled simply supported plate. In the first case the influence of the shells B and C on the plates A can be likened to attached springs, which increase the natural frequencies in comparison with a simply supported plate. In the second case their influence can be likened to attached masses, which decrease the natural frequencies. These results demonstrate that in the frequency range below $900 \mathrm{~Hz}$, the predominant influence of the flat plates A makes it possible to approximate the modal characteristics of QUASICAR by those for a simply supported flat plate having the dimensions of the flat sides. The above conclusion is confirmed also by the analytical derivations based on the coupled-wave theory approach [32].

The analysis of the experimental data (Table I, Column 4) shows some disagreements with the numerical results (Table I, Column 3). The experimental tests covered the frequency spectrum from 231 to $700 \mathrm{~Hz}$. In the low-frequency range, between 230 and $350 \mathrm{~Hz}$, it can be noticed that there is a large number of natural frequencies that do not correspond to those obtained from the numerical and analytical calculations. As a reason for the disagreement between experimental and numerical data in the whole range of frequencies one can point out the differences between the FE model and the real test rig, e.g. the unaccounted influence of masses 
of the accelerometers, imperfections in the boundary conditions, etc. In spite of these disagreements, the experimental analysis validates to some extent the numerical and analytical results and brings new ideas for further improvements of the experimental tests.

Table I Natural frequencies of the QUASICAR of the rectangular simply supported plate, and of the equivalent rectangular enclosure.

\begin{tabular}{|c|c|c|c|c|c|c|c|c|}
\hline \multicolumn{3}{|c|}{$\begin{array}{l}\text { Simply supported plate, } \\
\text { natural frequencies, } \mathrm{Hz}\end{array}$} & \multicolumn{2}{|c|}{$\begin{array}{l}\text { QUASICAR, } \\
\text { structural natural } \\
\text { frequencies, } \mathrm{Hz}\end{array}$} & \multicolumn{2}{|c|}{$\begin{array}{c}\text { Rectangle, acoustic } \\
\text { natural frequencies, } \\
\mathrm{Hz}\end{array}$} & \multicolumn{2}{|c|}{$\begin{array}{l}\text { QUASICAR, } \\
\text { acoustic natural } \\
\text { frequencies, } \mathrm{Hz}\end{array}$} \\
\hline & & 2 & 3 & 4 & & & 6 & 7 \\
\hline \multicolumn{2}{|c|}{ Analytical } & $\mathrm{FE}$ & $\mathrm{FE}$ & Exp. & Ana & ical & $\mathrm{FE}$ & Exp. \\
\hline$(1,1)$ & 59.04 & 59.18 & 67.035 & - & $(1,0,0)$ & 345.88 & 338.26 & 360.00 \\
\hline- & $\div$ & - & 67.039 & - & $(0,1,0)$ & 571.86 & 574.02 & 582.00 \\
\hline$(1,2)$ & 140.54 & 140.89 & 146.22 & - & $(1,1,0)$ & 668.32 & 666.27 & - \\
\hline- & - & - & 146.23 & - & $(0,0,1)$ & 686.23 & 668.84 & 685.00 \\
\hline$(2,1)$ & 154.68 & 155.10 & 157.67 & - & $(2,0,0)$ & 691.76 & 718.96 & - \\
\hline- & - & - & 157.67 & - & $(1,0,1)$ & 768.47 & 839.64 & - \\
\hline$(2,2)$ & 236.18 & 236.62 & 239.15 & 231.00 & $(0,1,1)$ & 893.27 & 881.39 & 894.00 \\
\hline- & - & - & 239.15 & - & $(2,1,0)$ & 897.53 & 920.00 & - \\
\hline$(1,3)$ & 276.36 & 277.12 & 264.51 & 265.00 & $(1,1,1)$ & 957.90 & 985.49 & - \\
\hline- & - & - & 264.52 & 270.00 & $(2,0,1)$ & 974.39 & 1017.10 & 980.00 \\
\hline$(3,1)$ & 314.08 & 314.99 & 315.33 & 281.00 & $(3,0,0)$ & 1037.64 & 1054.90 & - \\
\hline- & - & - & 315.33 & 297.00 & $(2,1,1)$ & 1129.81 & 1140.50 & - \\
\hline$(2,3)$ & 372.00 & 372.62 & 364.40 & 342.00 & $(0,2,0)$ & 1143.71 & 1162.20 & 1147.00 \\
\hline- & - & - & 364.40 & - & $(3,1,0)$ & 1184.79 & 1200.90 & - \\
\hline$(3,2)$ & 395.58 & 396.29 & 394.69 & 385.00 & $(3,0,1)$ & 1244.03 & 1210.40 & 1207.00 \\
\hline- & - & - & 394.69 & - & $(0,2,1)$ & 1333.79 & 1280.40 & - \\
\hline$(1,4)$ & 466.51 & 467.81 & 415.13 & 451.00 & $(3,1,1)$ & 1369.17 & 1318.20 & - \\
\hline- & - & - & 415.13 & - & $(0,0,2)$ & 1372.46 & 1340.90 & - \\
\hline$(3,3)$ & 531.40 & 531.95 & 521.45 & 523.00 & $(1,2,1)$ & 1377.91 & 1366.60 & - \\
\hline- & - & - & 521.45 & - & $(4,0,0)$ & 1383.53 & 1403.20 & 1407.00 \\
\hline$(4,1)$ & 537.25 & 538.77 & 529.53 & 545.00 & $(4,1,0)$ & 1497.05 & 1432.80 & - \\
\hline- & - & - & 529.54 & - & $(1,1,2)$ & 1526.53 & 1433.80 & 1521.00 \\
\hline$(2,4)$ & 562.15 & 563.07 & 538.04 & - & $(4,0,1)$ & 1544.36 & 1437.70 & - \\
\hline- & - & - & 538.04 & - & $(4,1,1)$ & 1646.84 & 1486.00 & 1645.00 \\
\hline$(4,2)$ & 618.74 & 619.85 & 601.92 & - & $(0,3,0)$ & 1715.57 & 1523.80 & - \\
\hline- & - & - & 601.93 & - & $(5,0,0)$ & 1729.41 & 1543.50 & 1750.00 \\
\hline$(1,5)$ & 710.98 & 712.91 & 615.62 & 652.00 & $(5,1,0)$ & 1821.50 & 1569.60 & $\div$ \\
\hline- & - & - & 615.62 & - & $(0,3,1)$ & 1847.73 & 1593.00 & 1847.00 \\
\hline$(3,4)$ & 721.55 & 721.99 & 691.67 & 700.00 & $(5,0,1)$ & 1860.58 & 1593.30 & - \\
\hline- & - & - & 691.68 & - & $(1,3,1)$ & 1879.82 & 1626.10 & 1872.00 \\
\hline
\end{tabular}

\subsection{Independent acoustic analysis of QUASICAR}

The analysis of the acoustic data (see Table I, Columns 5, 6, 7 and Fig. 10) shows a good agreement between analytical, numerical and experimental results in the frequency range up to $1000 \mathrm{~Hz}$. This implies that the use of the well known analytical formulae for the equivalent rectangular enclosure is the easiest way for a quick verification of numerical or experimental results. Above $1000 \mathrm{~Hz}$ the precision of the numerically determined natural frequencies is reduced, which is due to a smaller number of finite elements per wavelength. The differences between measured and numerically calculated acoustic natural frequencies may be partly explained by the unaccounted rectangular gap in the left-hand side part of QUASICAR's shell test rig.

\subsection{Independent structural analysis of the modified model MI}

The geometry and the boundary conditions of the model $\mathbf{M 1}$ are the same as those shown in Fig. 6. As was mentioned above, the only difference is the higher thickness of the bottom flat part of the shell that has been increased to $6.0 \mathrm{~mm}$. In this way the symmetry in respect of the central horizontal plane of QUASICAR has been broken, which corresponds more realistically to the case of real vehicles having higher 
stiffness of the floor area. A normal mode FE analysis was performed for the first 20 normal modes, and the FE model employed in total 10287 nodes and 10000 isomesh CQUAD4 surface elements.

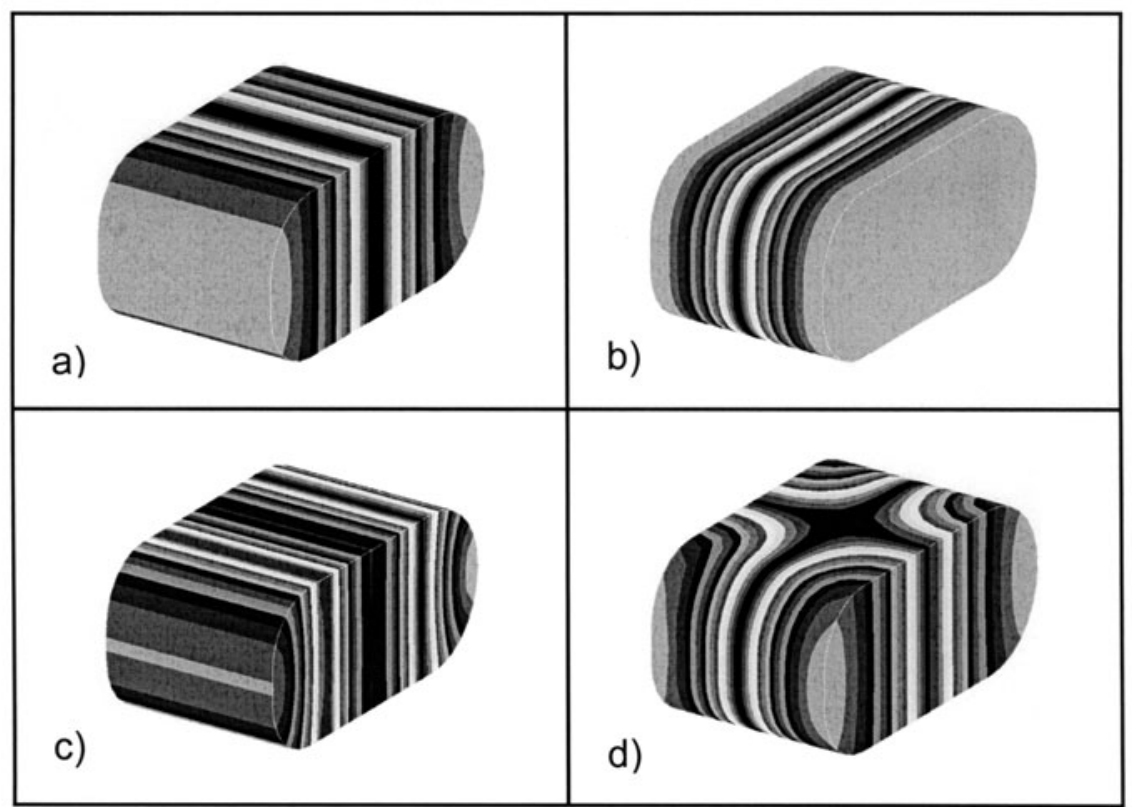

Figure 10:

QUASICAR's first acoustic modes: a) (I,0,0)-338.26 Hz, b) $(0,0, \mathrm{I})-574.02 \mathrm{~Hz}, \mathrm{c})(2,0,0)-668.84$ $\mathrm{Hz}$ and d) $(\mathrm{I}, 0, \mathrm{I})-666.27 \mathrm{~Hz}$

Comparing the normal modes of the modified model MI (Fig. 11) and its natural frequencies (Table II, Column 1) with those of QUASICAR (Table II Column 4), one can notice some interesting facts. First of all, the predominant locations of vibrations in different modes are in one of the main parts of the model: the bottom flat part, the top flat part or the curved side parts. Only in a few modes, in the considered frequency range $0-1000 \mathrm{~Hz}$, all three parts are involved. The distinctive normal modes are associated with the different stiffness of the parts, while their geometrical forms remain the same. Secondly, in spite of the change of the model from QUASICAR to $\boldsymbol{M 1}$ (increase in mass and stiffness of the bottom part), the fundamental natural frequencies remain unchanged. Indeed, they are defined by the top plate, which has the lowest stiffness and was unchanged after the modification. Except for the first three natural frequencies, the resonances do not match well and go down compared with the QUASICAR natural frequencies. The difference between both sets of resonant frequencies for higher-order modes, of course, was expected and reflects the influence of the additional mass and stiffness of the bottom plate. Suppressing of the participation of the bottom part of the shell in the formation of normal modes is another important feature demonstrated here. In the frequency range between 0 and $1000 \mathrm{~Hz}$ the bottom part is involved only in the five normal modes: at $224.37 \mathrm{~Hz}, 391.51 \mathrm{~Hz}, 653.34 \mathrm{~Hz}, 682.27 \mathrm{~Hz}$, and $844.27 \mathrm{~Hz}$, whereas in QUASICAR model the bottom plate always plays the same role as the top one. Thus, the modified model $\boldsymbol{M l}$, which is closer to real road vehicles than the QUASICAR model, demonstrates some useful ideas for controlling the vibration behaviour of car body structures and in the same time keeps me calculations simple.

\subsection{Coupled structural-acoustic analysis}

5.4.I Free vibration analysis (normal mode analysis)

Interaction or coupling between the enclosed air and the structure means their mutual influence on the dynamic behaviour of each other. The air acts via its pressure on the structural surface, and at the same time it is influenced by the normal displacements of the structure $[4,5]$. Thus, the air pressure on the surface is considered as a disturbing force in the governing equations of motion of the 
structure and the normal accelerations of the structural surface enter into the Helmholtz equation via 'flexible wall' boundary conditions. Coupling of these equations leads to a single governing matrix equation for the whole system airstructure (see Eqn.(6)) .

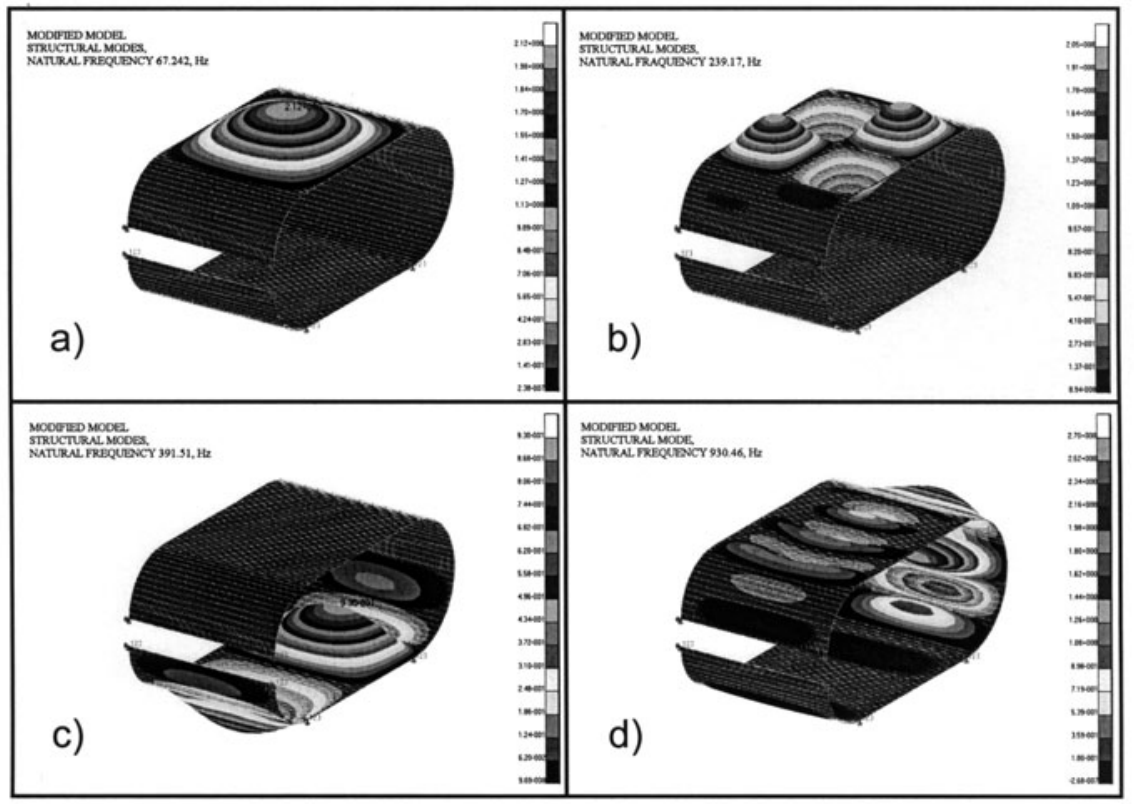

Figure II: $\quad$ Structural modes of the modified model MI: a) $67.242 \mathrm{~Hz}$, b) $239.17 \mathrm{~Hz}$, c) $391.5 \mathrm{~Hz}$ and d) $930.46 \mathrm{~Hz}$

In the coupled structural-acoustic analysis we have considered in detail the coupling of the first rigid-wall acoustic mode at $338.26 \mathrm{~Hz}$ with different structural modes 'in vacuo'. The energy of the coupled mode is divided between structural vibrations and air motions. In this respect, from the results shown in Table II, one cam distinguish "acoustic" and "structural" modes of the coupled QUASICAR model (Column 5) and of the coupled modified model M1 (Column 2). The coupling between acoustic and structural modes depends on their spatial similarity and frequency closeness, as shown in section 2. The structural spatial patterns of QUASICAR and modified model $\boldsymbol{M 1}$ are two-dimensional; this means that structural modes will correspond best to the acoustic modes in the area of the relevant two-dimensional acoustic spatial patterns.

Figure 12 and Fig. 13 show the normal modes of the coupled QUASICAR and M1 models affected by the first rigid-wall acoustic mode. The acoustic uncoupled mode at $338.26 \mathrm{~Hz}$ and with $(1,0,0)$ spatial pattern influences some QUASICAR structural modes with spatial patterns $(2,3)$ at $394.69 \mathrm{~Hz}$, and $(4,1)$ at $415.33 \mathrm{~Hz}$ and some structural modes of modified model $\boldsymbol{M 1}$ with spatial patterns $(2,1)$ at 396.25 $\mathrm{Hz}$, and $(4,1)$ at $421.58 \mathrm{~Hz}$. Comparing the coupled QUASICAR modes at 394.69 $\mathrm{Hz}$ and at $421.90 \mathrm{~Hz}$, one can notice that the better matching of the structural and acoustic spatial patterns in the latter mode, in spite of its remoteness from the rigidwall frequency, leads to a more distinctive picture of the coupling rather than for the previous normal mode.

Another interesting point is a great alteration of the fundamental frequency of the coupled models. As was pointed out by Fahy [5], this phenomenon is due to a strong coupling of the first structural mode with the zero-order acoustic mode $(0,0,0)$ having zero natural frequency, as was mentioned also in section 2. Usually, the first cavity resonance frequency is above the fundamental structural frequency and coupling effects occur at frequencies above the first acoustic resonance, except for this case when the coupling occurs at frequency lower than the first acoustic peak. In this connection, one can recall that QUASICAR model has two groups of natural frequencies: symmetric and anti-symmetric. Finite element analysis shows that only 
symmetric modes can couple efficiently with the acoustic modes. This might be because in anti-symmetric structural modes the air inside the cavity moves as a rigid body and does not exhibit acoustic behaviour. The influence of the air on structural vibrations in anti-symmetric modes is also less pronounced than in the case of symmetric modes. This is why the natural frequencies of symmetric and antisymmetric structural modes in a coupled model have greater differences than in the case of the same structural modes in an uncoupled model, particularly for the fundamental modes.

Table II Numerical results for the modified model MI and for structuralacoustic interaction in me QUASICAR model.

\begin{tabular}{|c|c|c|c|c|c|}
\hline \multicolumn{2}{|c|}{$\begin{array}{l}\text { Model } M I \text {, uncoupled } \\
\text { (1) and coupled (2) } \\
\text { natural frequencies, } \mathrm{Hz}\end{array}$} & \multicolumn{2}{|c|}{$\begin{array}{c}\text { QUASICAR } \\
\text { uncoupled (4) and } \\
\text { coupled (5) natural } \\
\text { frequencies, } \mathrm{Hz}\end{array}$} & \multirow{2}{*}{\multicolumn{2}{|c|}{$\begin{array}{c}\begin{array}{c}\text { Acoustic } \\
\text { uncoupled } \\
\text { natural }\end{array} \\
\text { frequencies, } \mathrm{Hz}\end{array}$}} \\
\hline 1 & 2 & 4 & 5 & & \\
\hline 67.242 & 72.313 & $\begin{array}{l}67.035 \\
67.039 \\
\end{array}$ & $\begin{array}{l}67.909 \\
76.488 \\
\end{array}$ & & \\
\hline 146.74 & 148.78 & $\begin{array}{l}146.22 \\
146.23\end{array}$ & $\begin{array}{l}148.61 \\
148.97\end{array}$ & & \\
\hline 157.69 & 156.53 & $\begin{array}{l}57.67 \\
157.67 \\
\end{array}$ & $\begin{array}{l}156.47 \\
156.59 \\
\end{array}$ & & \\
\hline 224.37 & 227.21 & $\begin{array}{l}239.15 \\
239.15\end{array}$ & $\begin{array}{l}237.71 \\
237.77\end{array}$ & & \\
\hline 239.17 & 237.74 & $\begin{array}{l}264.51 \\
264.52 \\
\end{array}$ & $\begin{array}{l}270.03 \\
270.44\end{array}$ & & \\
\hline 265.50 & 270.23 & $\begin{array}{l}15.33 \\
315.33\end{array}$ & $\begin{array}{l}311.98 \\
312.25\end{array}$ & & \\
\hline & 338.09 & & 338.59 & $(1,0,0)$ & 338.26 \\
\hline 364.37 & 362.67 & $\begin{array}{l}364.40 \\
364.40 \\
\end{array}$ & $\begin{array}{l}362.63 \\
362.70 \\
\end{array}$ & & \\
\hline 391.51 & 386.70 & $\begin{array}{r}394.69 \\
394.69 \\
\end{array}$ & $\begin{array}{l}386.57 \\
386.83 \\
\end{array}$ & & \\
\hline 393.81 & 396.25 & $\begin{array}{l}415.13 \\
415.13 \\
\end{array}$ & $\begin{array}{r}421.29 \\
421.90 \\
\end{array}$ & & \\
\hline 416.25 & 421.58 & $\begin{array}{l}521.45 \\
521.45 \\
\end{array}$ & $\begin{array}{l}505.64 \\
505.67 \\
\end{array}$ & & \\
\hline 519.43 & 505.66 & $\begin{array}{r}529.53 \\
529.54 \\
\end{array}$ & $\begin{array}{l}527.01 \\
527.13 \\
\end{array}$ & & \\
\hline 529.20 & 527.07 & $\begin{array}{l}538.04 \\
538.04 \\
\end{array}$ & $\begin{array}{l}532.27 \\
532.93 \\
\end{array}$ & & \\
\hline & 574.68 & & 575.89 & $(0,1,0)$ & 574.02 \\
\hline 603.27 & 602.87 & $\begin{array}{l}601.92 \\
601.93\end{array}$ & $\begin{array}{l}602.78 \\
602.96\end{array}$ & & \\
\hline 613.52 & 608.83 & $\begin{array}{l}615.62 \\
615.62\end{array}$ & $\begin{array}{l}608.83 \\
608.90\end{array}$ & & \\
\hline
\end{tabular}


Simplified Modelling of Vehicle Interior Noise:

Comparison of Analytical, Numerical and Experimental Approaches

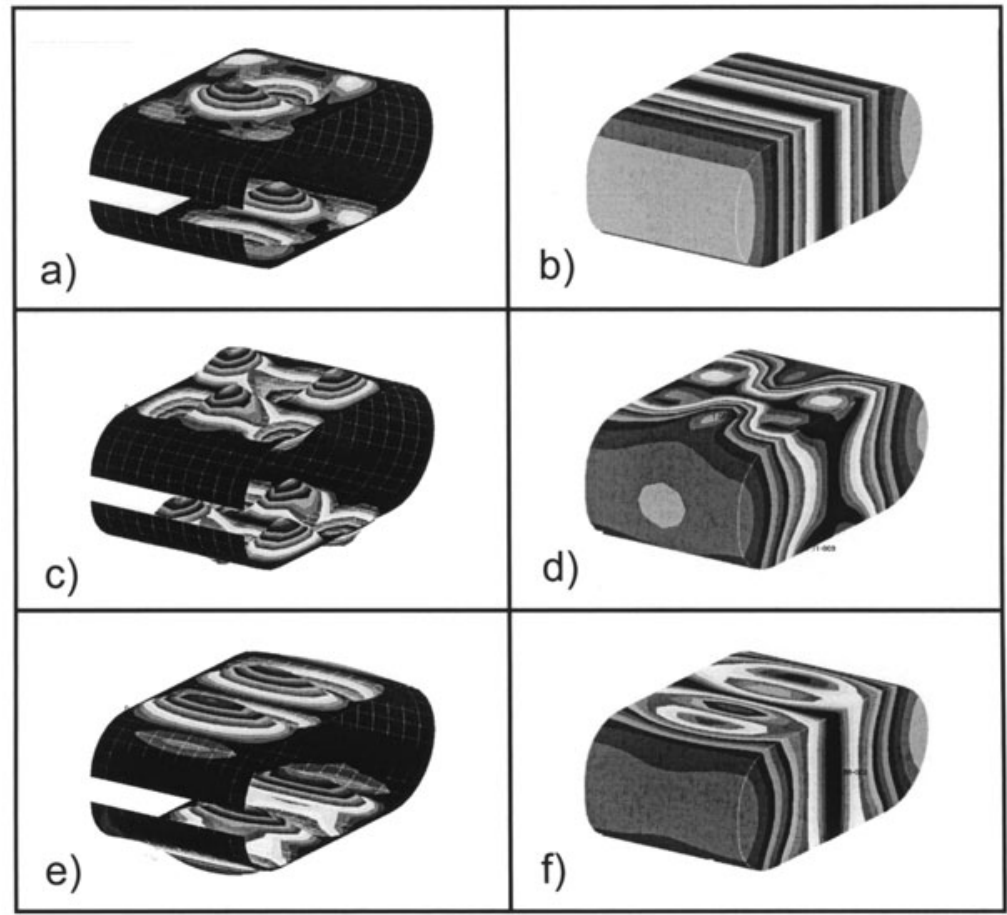

Figure 12: $\quad$ QUASICAR's coupled modes: structural modes (left) and acoustic modes (right): a, b) $338.59 \mathrm{~Hz}$, c, d) $386.83 \mathrm{~Hz}$ and e, f) $421.90 \mathrm{~Hz}$.

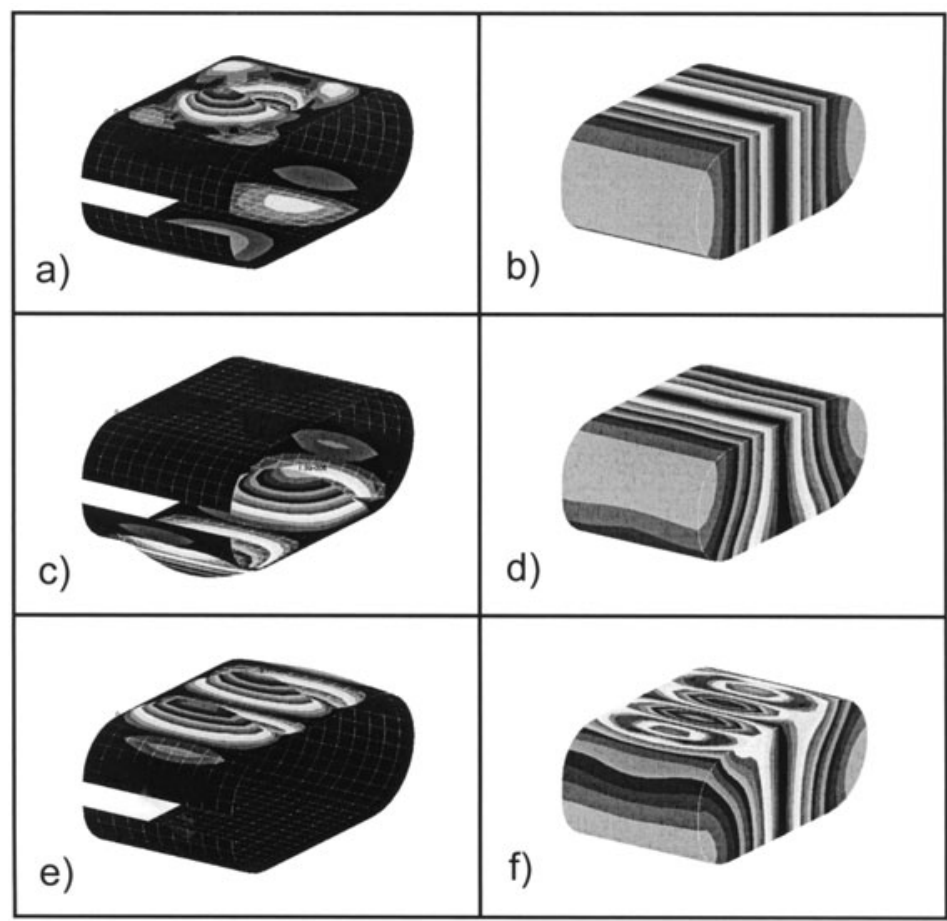

Figure 13: $\quad$ Coupled modes of the modified model MI: strucural modes (left) and acoustic modes (right): a, b) $338.09 \mathrm{~Hz}, \mathrm{c}$, d) $396.25 \mathrm{~Hz}$ and e, f) $421.58 \mathrm{~Hz}$.

5.4.2 Forced vibration analysis (frequency response analysis)

In the previous sections free vibrations of the uncoupled and coupled simplified vehicle models were considered as their modal parameters were determined. However, to estimate the interior noise due to external or internal disturbing dynamic forces, it is necessary to carry out a forced vibration analysis. In Fig. 14 and Fig. 15 one can see the results of numerical calculations for magnitudes and 
phases of the FRF's of the QUASICAR model and of the modified model $\mathbf{M 1}$ respectively. The solutions are rather typical for forced dynamic systems, with the presence of resonant peaks at different frequencies. Note that in the case under consideration the resonance peaks appear at the natural frequencies of the coupled modes. The phases of the FRFs show regions of positive and negative values corresponding to the interior sound pressure and the disturbing force being in phase and out of phase. Comparing the resulting interior noise for these two models calculated for the same disturbing force one can notice the reduction of the interior sound pressure levels in the modified model $\boldsymbol{M 1}$, which apparently is due to the higher thickness of its bottom part.

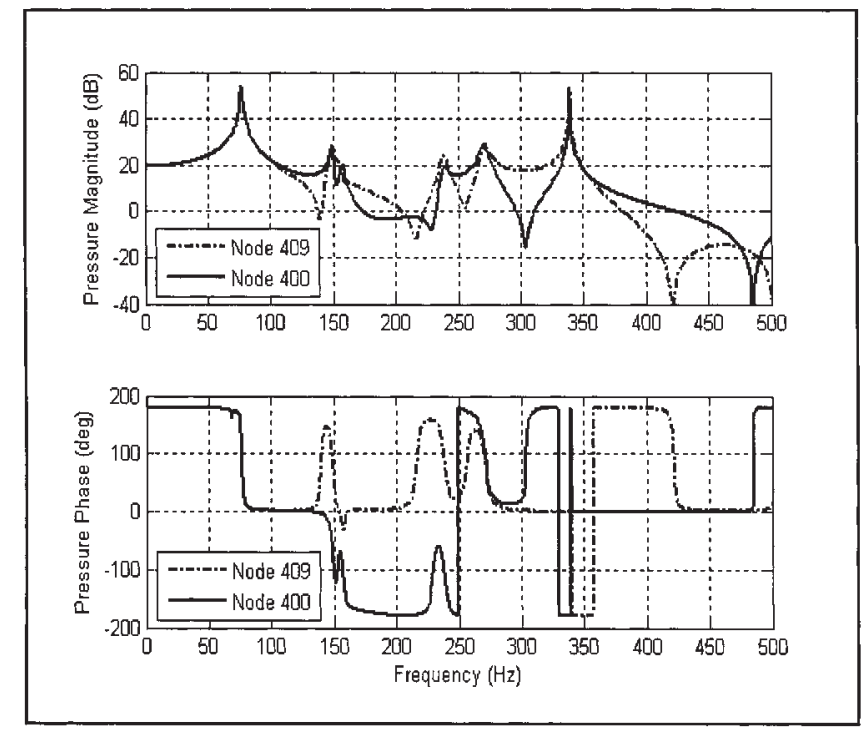

Figure 14: Numerically calculated amplitude and phase frequency response functions at nodes 400 (solid) and 409 (dash-dotted) in QUASICAR model.

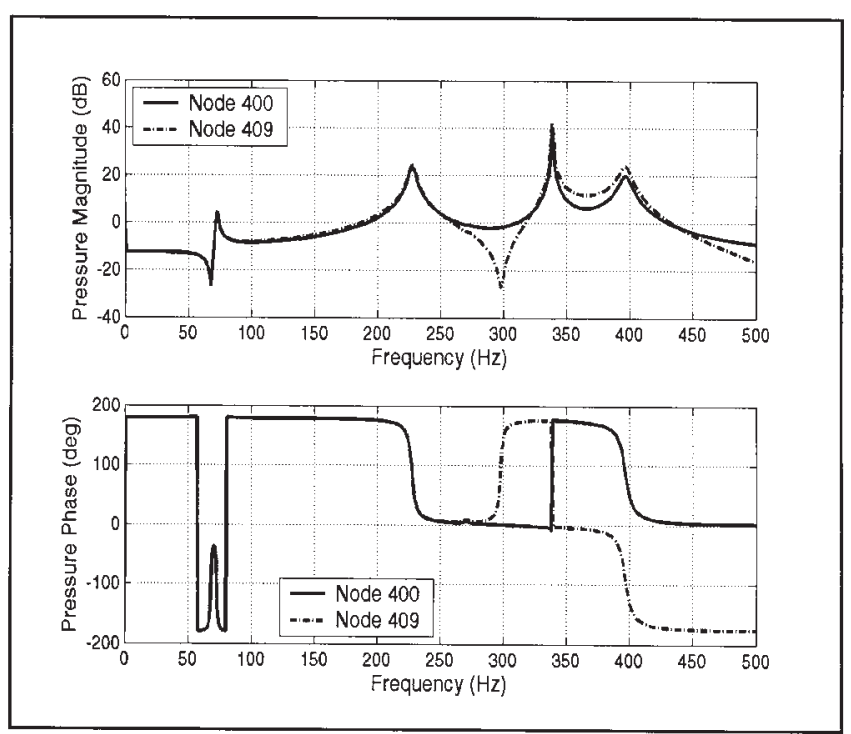

Figure 15: $\quad$ Numerically calculated amplitude and phase frequency response functions at nodes 400 (solid) and 409 (dash-dotted) $\mathrm{m}$ the modified model MI .

Experimental measurements of amplitudes and phases of FRFs have been carried out for the QUASICAR model only. The results can be seen in Fig. 16 and Fig. 17 for the locations corresponding to the above-mentioned nodes 400 and 409 respectively. It can be seen that there is a certain agreement between the two sets of data for QUASICAR, the predicted and measured. All numerically calculated 
resonant peaks are visible in the measured FRF's, thus confirming that the numerical results obtained are reliable.

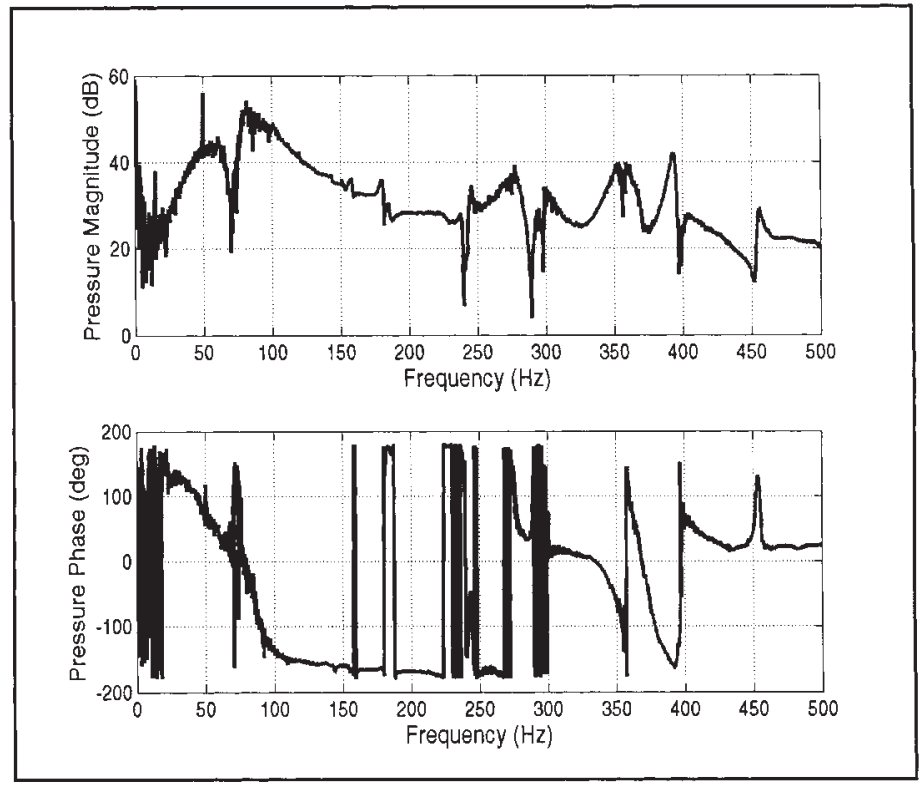

Figure 16: Measured amplitude and phase frequency response functions at node 400 in QUASICAR model.

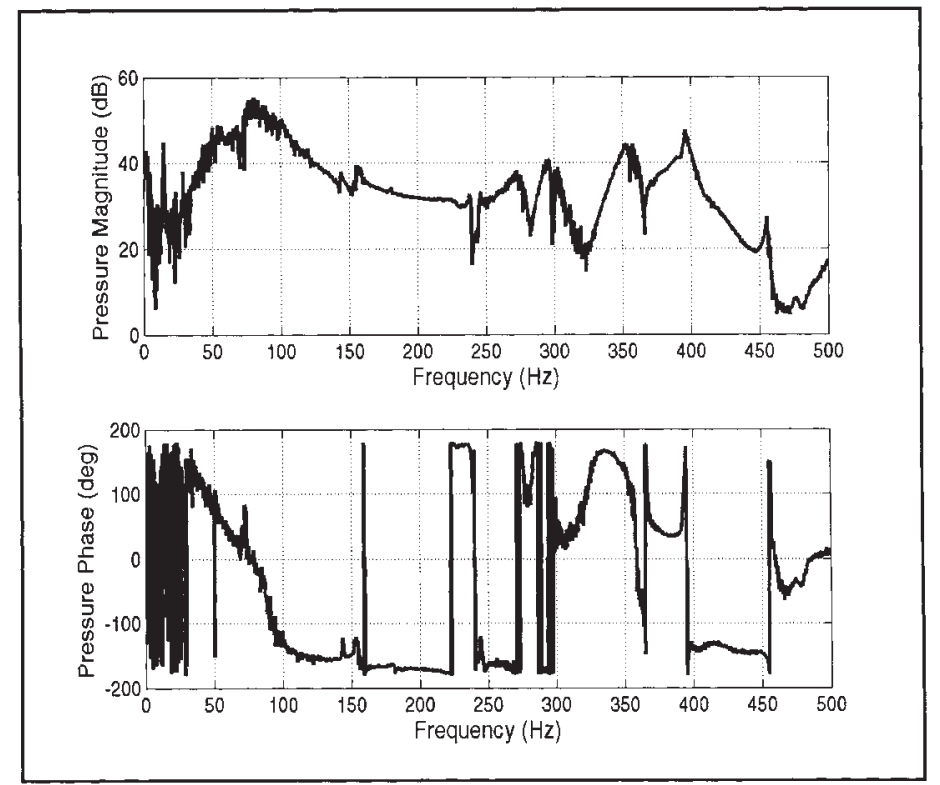

Figure 17: Measured amplitude and phase frequency response functions at node 409 in QUASICAR model.

Some discrepancies between the numerical and experimental data can be partly explained by high sensitivity of FRF's to the exact location of the response point. Therefore, unavoidable errors in the placement of the microphone at locations corresponding to the nodes 400 and 409 might have resulted in changes in the measured FRFs.

5.5 Comparison between analytical and numerical acoustic pressure responses

Figures 18 and 19 show the comparison between the acoustic pressure responses at nodes 400 and 409 respectively for the QUASICAR model calculated numerically 
and using the analytical approach (Eqns. (1)-(3)). Both figures demonstrate a relatively good coincidence between analytical and numerical results. The observed areas of disagreement apparently reflect the consequences of the applied approximation of the QUASICAR acoustic cavity by the equivalent rectangular box. It is more interesting and useful, however, to discuss the areas of the observed agreement between the results of the two approaches.

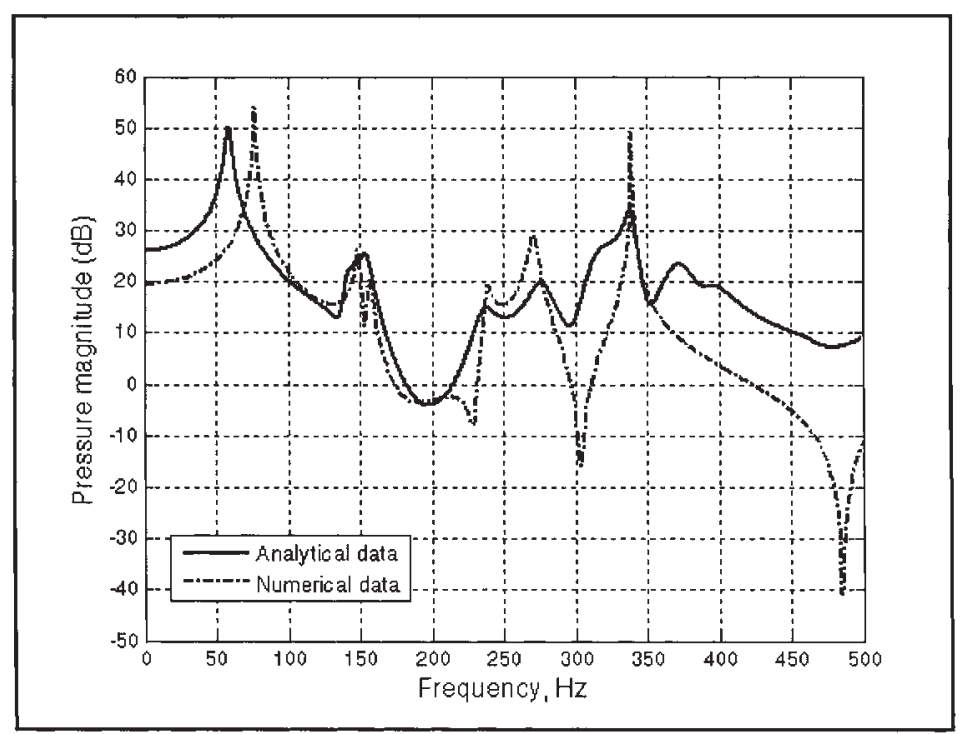

Figure 18: Comparison of the analytically (solid curve) and numerically (dash-dotted curve) calculated FRF's of me QUASICAR at node 400.

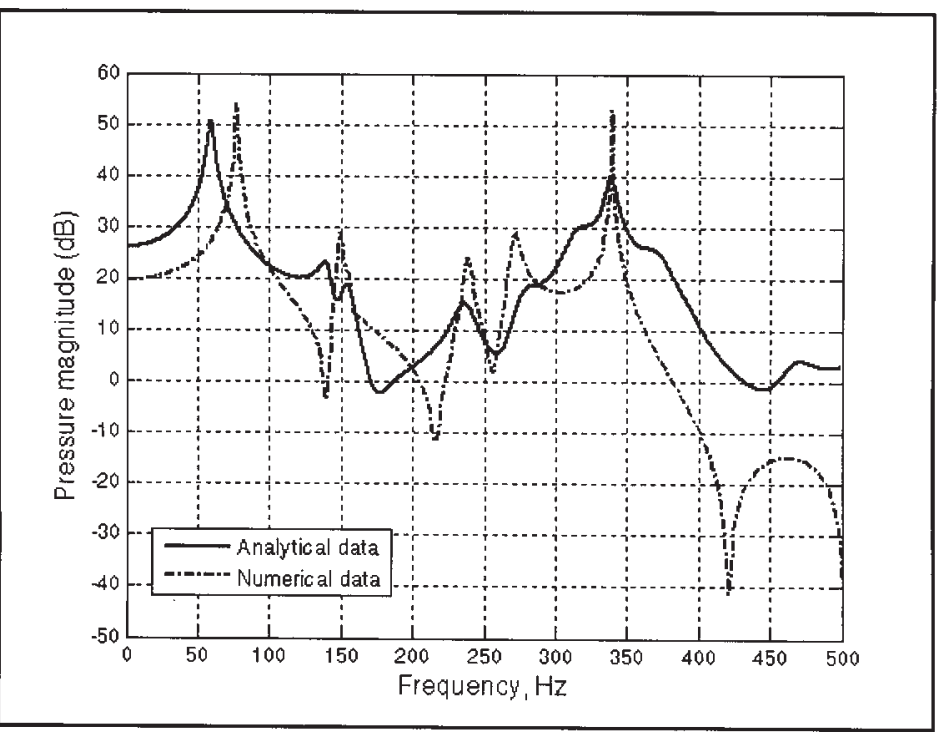

Figure 19: Comparison of the analytically (solid curve) and numerically (dash-dotted curve) calculated FRF's of the QUASICAR at node 409.

First of all, we recall that the vibrating structure used in the analytical formula is a plate having the same dimensions as the top and bottom quasi-flat parts in the QUASICAR structure. As was shown in section 5.1, the predominant vibrations of QUASICAR model are concentrated on the flat plates in the range from 0 to around $700 \mathrm{~Hz}$. This is why most of the structural resonances coincide well for both figures. The discrepancies can be partly explained by the difference in boundary conditions for the vibrating plates. Therefore, one can conclude that for simplification of a complex model in a certain frequency range it is enough to construct only its main 
structural panel which contributes most to the total vibration response in this range.

Although the locations of the resonant frequencies show a good agreement, the amplitudes of the resonant peaks are comparatively different. The same parameters were used in the calculations of both pressure responses: attenuation factors, disturbing forces, positions of the disturbing force, and positions of the receiver point. The most likely reason for the discrepancies in the peak amplitudes could be uncertainty in the location of the receiver point. In spite of the fact that this position has the same coordinates, its distances from the real models' walls appear to be different because of the above-mentioned approximation of the QUASICAR interior by the equivalent rectangular enclosure. Therefore, although the approximation of the model's acoustic cavity by a rectangular enclosure with the same volume is possible and yields relatively good results, it can not guarantee the exact position of the receiver point and consequently the same amplitudes for these observed resonant peaks.

\section{CONCLUSIONS}

In the present paper the results of analytical, numerical and experimental approaches to modelling structure-borne interior noise in the simplified vehicle model QUASICAR and its modification have been reported. The study began with a discussion and validation of the analytical expressions using the simplest model of a rigid box with one flexible wall. The numerical calculations have been carried out for free vibrations and forced structural-acoustic responses of the simplified model. Initially, the structural and acoustic parts have been considered separately and then as a fully coupled model. Along with the analytical and numerical studies, a number of experimental FRF's have been obtained.

In the uncoupled model, the normal modes of me structure and the acoustic modes of the enclosure have been calculated. It has been found that in the low frequency range the structural vibrations of the QUASICAR can be approximated by those of simply supported plates corresponding to the flat parts of the structure. The analysis of the modified model $\boldsymbol{M I}$ has provided useful information on the effect of the thickness of the bottom part of the structure on the normal mode distribution.

In the coupled models QUASICAR and modified model $\mathbf{M 1}$ the interaction between structures and the enclosed air has been studied. It has been found that spatial similarity between structural and acoustic normal modes is a prerequisite for a better coupling even if the structural and acoustic natural frequencies do not match well. This was also clearly shown in the analysis of the analytical formula for acoustic pressure response.

The pressure frequency responses to a forced structural excitation in the coupled models QUASICAR and $\boldsymbol{M I}$ have been calculated as well. It has been shown that the level of structure-borne interior noise in the model $\boldsymbol{M 1}$ is lower than in the QUASICAR due to the increased thickness of the bottom part of the structure. The FE resonant peaks were visible in the experimental FRF's for the same response points.

Lastly, analytical and numerical FRF's have been compared for the QUASICAR model. The results have shown a reasonably good agreement. This proves the possibility of using analytical approaches for analysis of rather complex structures, in comparison with the simplest classical model comprising a rigid rectangular box with one flexible wall. In this regard, the present paper represents a step forward in understanding physical mechanisms of structure-borne vehicle interior noise. It is anticipated that the introduction of more complex but still manageable structural models reflecting the complexity of real vehicles will lead to the development of efficient analytical and experimental tools that could be suitable for quick prediction of vehicle interior noise at a design stage. The key issue here is to find a compromise between the minimum degree of complexity of a model and the required accuracy of description of frequency contents and noise levels in a vehicle. 


\section{REFERENCES}

[1] M. Pozar, H.E. Cook: On determining the relationship between vehicle value and interior noise. SAE 980621 (1998) Intemational Congress \& Exposition, Detroit, MI.

[2] R. Bisping, S. Giehl, M. Vogt: A standardised scale for the assessment of car interior sound quality. SAE 971976 (1997).

[3] S.K. Jha: Characteristics and sources of noise and vibration and their control in motor cars. Journal of Sound and Vibration 46 (1976) 543-558.

[4] M.C. Junger, D. Feit: Sound, structures and their interaction. Cambridge MA MIT Press (1972).

[5] F. Fahy: Sound and structural vibration. London; Academic Press (1985).

[6] C.K. Song, J.K. Hwang, J.M. Lee, J.K. Hedrick: Active vibration control for structural-acoustic coupling system of a 3-D vehicle cabin model. Joumal of Sound and Vibration 267 (2003) 851 -865.

[7] S.H. Kim, J.M. Lee: Practical method for noise reduction in a vehicle passenger compartment. Journal of Vibration and Acoustics 120 (1998) 199205.

[8] A.J. Pretlove: Free vibrations of a rectangular panel backed by a closed rectangular cavity. Journal of Sound and Vibration, 2 (1965), 197-209.

[9] A.J. Pretlove, Forced vibrations of a rectangular panel backed by a closed rectangular cavity. Journal of Sound and Vibration, 3 (1966), 252-261.

[10] R.H. Lyon: Noise reduction of rectangular enclosures with one flexible wall, J. Acoust. Soc. Am., 35 (1963), pp 1791-1797.

[11] G.H. Koopmann, H.F. Pollard: A joint acceptance function for structuralacoustical coupling problems. Journal of Sound and Vibration, 46(2) (1976), 302-305.

[12] G.H. Koopmann, H.F. Pollard: A joint acceptance function for enclosed spaces. Journal of Sound and Vibration, 73(3) (1980), 429-446.

[13] S.H. Sung, D.J. Nefske, H. Le-The, F. Bonarens: Development and experimental evaluation of a vehicle structural-acoustic trimmed-body model. SAE 1999-01-1798 (1999) Noise \& Vibration Conference \& Exposition, Traverse City, MI.

[14] T.C. Lim: Automotive panel noise contribution modelling based on finite element and measured structural-acoustic spectra.Applied Acoustics 60(2000)505-519.

[15] M. Petyt, J. Lea, G.H. Koopmann: A finite element method for determining the acoustic modes of irregular shaped cavities. Journal of Sound and Vibration 45 (1976) 495-502.

[16] T.L. Richards, S.K. Jha: A simplified finite element method for studying acoustic characteristics inside a car cavity. Journal of Sound and Vibration $\mathbf{6 3}$ (1979) 6172. 
[17] D.J Nefske, J.A. Wolf Jr, L.J. Howell: Structural-acoustic finite element analysis of the automobile passenger compartment: a review of current practice. Journal of Sound and Vibration 80 (1982) 247-266.

[18] S.H. Sung, D.J. Nefske: A coupled structural-acoustic finite element model for vehicle interior noise analysis, J. Vibr., Acoust., Stress, Reliab. Design, Trans. of the ASME, 106 (1984), pp 314-318.

[19] A. Sol, F. Van Herpe: Numerical prediction of a whole car vibro-acoustic behaviour at low frequencies. SAE 2001-01-1521 (2001). SAE Noise \& Vibration Conference \& Exposition, Grand Traverse, Ml.

[20] W. Stokes, J. Bretl, A. Crewe, W.S. Park, J.Y. Lee, M.Y. Lee: Computer simulation of in-vehicle boom noise.SAE 971914(1997).

[21] W.L. Li, P.E. Cho: CAE tools for structural acoustic analysis. SAE 952117 (1995).

[22] R.H. Lyon: Statistical energy analysis of dynamical systems. MIT Press, Cambridge, MA (1975)

[23] J.A. Nore, R. Powell, T. Bharj: Development of condensed SEA models of passenger vehicles. SAE 1999-01-1699 (1999) Noise \& Vibration Conference \& Exposition, Traverse City, Ml.

[24] W.G. Lee, S.K. Park, M.W. Suh: A study on active noise control using the half scaled compartment cavity model. SAE 940606 (1994).

[25] E.Y. Nakanishi: Acoustic modal analysis for vehicle cabin. SAE 952246 ( 1995).

[26] L.E. Schroeder: Feasibility of using acoustic room models and measured sound power to estimate vehicle interior noise. SAE 2001-01-1533 (2001) SAE Noise \& Vibration Conference \& Exposition, Grand Traverse, Ml.

[27] R. Gorman, V.V. Krylov: Investigation of acoustic properties of vehicle compartments using reduced-scale simplified models. Proceedings of the Institute of Acoustics 26 (2004) 37-48.

[28] Youn-Sik Park, Yong-Hwa Park,: Vehicle interior noise and vibration reduction using experimental structural dynamics modification. SAE 971915 (1997).

[29] R. Rashid, R.S. Langley: A hybrid method for modelling in-vehicle boom noise. Proceedings of ISMA Prague (2004) 3487-3500.

[30] V.V. Krylov: Simplified analytical models for prediction of vehicle interior noise. Proceedings of the Intemational Conference on Noise and Vibration Engineering ISMA Belgium 5 (2002) 1973-1980.

[31] V.V. Krylov, S.J. Walsh, and R.E.T.B. Winward: Modelling of vehicle interior noise at reduced scale, Proceedings of Euronoise 2003, Naples, 2003 (on CD).

[32] V.V. Krylov and V.B. Georgiev: Coupled-wave theory approach to understanding resonant vibrations of non-circular cylindrical shells, Proceedings of the Institute of Acoustics, 26 (2004), Pt.2, 139-146. 


\section{LIST OF ABBREVIATIONS}

$\mathrm{a}_{\mathrm{m}} \quad$ coefficients depending on shape of the enclosure and on mode type

c speed of sound

$\{\mathbf{F}\} \quad$ vector of disturbing dynamic forces

$\mathrm{F}_{\mathrm{mp}}(\omega) \quad$ frequency overlap function

$\mathrm{h}_{\mathrm{s}} \quad$ thickness of a flexible plate

\{I $\}$ vector of normalised forces applied to the fluid over am element surface

i imaginary unit

$\left[\mathbf{K}^{a}\right] \quad$ acoustic stiffness matrix

$\left[\mathbf{K}^{s}\right] \quad$ structural stiftness matrix

$\left[\mathbf{K}^{s a}\right] \quad$ structural-acoustic coupling stiffness matrix

$\mathrm{L}_{\mathrm{x}, \mathrm{eq}}, \mathrm{L}_{\mathrm{y}}, \mathrm{L}_{\mathrm{z}}$ dimensions of me equivalent rectangular box having the same volume as that of the QUASICAR enclosure

$\mathrm{L}_{\mathrm{x}}, \mathrm{L}_{\mathrm{y}}, \mathrm{L}_{\mathrm{z}}$ overall dimensions of the QUASICAR model

$\mathrm{L}_{\mathrm{x} 0}, \mathrm{~L}_{\mathrm{x} 1} \quad$ boundary coordinates in $\mathrm{X}$ direction of the vibrating quasi-flat flexible wall of the QUASICAR model

$\mathrm{m}$ index of structural modes (2 dimensional)

$\left[\mathbf{M}^{a}\right] \quad$ acoustic mass matrix

$\left[\mathbf{M}^{a s}\right] \quad$ structural-acoustic coupling mass matrix

$\left[\mathbf{M}^{s}\right] \quad$ structural mass matrix

$\mathrm{P} \quad$ amplitude of a driving harmonic force

$\{\mathbf{p}\} \quad$ vector of nodal sound pressures

$\mathrm{p} \quad$ index of acoustic modes (3 dimensional)

$\left\{\mathbf{p}^{b}\right\} \quad$ vector of nodal sound pressures at boundary surface

$\mathrm{p}(\mathbf{r}) \quad$ acoustic pressure inside the enclosure at a point $\mathrm{r}$

[S] structural-acoustic coupling matrix

$\mathrm{S}_{\mathrm{mp}} \quad$ coefficients of structural-acoustic coupling

V volume of the enclosure

$\{\mathbf{v}\} \quad$ vector of structural displacements

$\delta_{\mathrm{m}}, \delta_{\mathrm{p}} \quad$ structural and acoustic attenuation factors, respectively 
Simplified Modelling of Vehicle Interior Noise:

Comparison of Analytical, Numerical and Experimental Approaches

$\rho_{\mathrm{a}}, \rho_{\mathrm{s}} \quad$ mass densities of fluid and structure, respectively

$\phi_{\mathrm{m}}(\mathbf{r}) \quad$ acoustic modal shapes for a rectangular enclosure

$\psi_{\mathrm{p}}(\rho) \quad$ structural modal shapes for a rectangular plate

$\omega \quad$ driving frequency

$\omega_{\mathrm{m}}, \omega_{\mathrm{p}} \quad$ structural and acoustic natural frequencies, respectively 